\title{
Findings of Hydrogen Internal Combustion Engine Durability
}

\author{
Final Technical/Scientific Report
}

Project Period: 3/7/07 - 12/31/2010

\author{
Garrett P. Beauregard \\ March 31, 2011 \\ DE-FC26-06NT43027 \\ Electric Transportation Engineering Corporation \\ 430 S. $2^{\text {nd }}$ Ave \\ Phoenix, AZ 85003
}

\begin{abstract}
"This report was prepared as an account of work sponsored by an agency of the United States Government. Neither the United States Government nor any agency thereof, nor any of their employees, makes any warranty, express or implied, or assumes any legal liability or responsibility for the accuracy, completeness, or usefulness of any information, apparatus, product, or process disclosed, or represents that its use would not infringe privately owned rights. Reference herein to any specific commercial product, process, or service by trade name, trademark, manufacturer, or otherwise does not necessarily constitute or imply its endorsement, recommendation, or favoring by the United States Government or any agency thereof. The views and opinions of authors expressed herein do not necessarily state or reflect those of the United States Government or any agency thereof."
\end{abstract}




\begin{abstract}
Hydrogen Internal Combustion Engine (HICE) technology takes advantage of existing knowledge of combustion engines to provide a means to power passenger vehicle with hydrogen, perhaps as an interim measure while fuel cell technology continues to mature. This project seeks to provide data to determine the reliability of these engines. Data were collected from an engine operated on a dynamometer for 1000 hours of continuous use. Data were also collected from a fleet of eight (8) full-size pickup trucks powered with hydrogen-fueled engines. In this particular application, the data show that HICE technology provided reliable service during the operating period of the project. Analyses of engine components showed little sign of wear or stress except for cylinder head valves and seats. Material analysis showed signs of hydrogen embrittlement in intake valves.
\end{abstract}




\section{Table of Contents}

\section{Table of Contents}

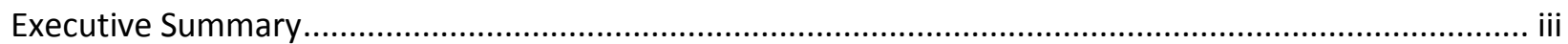

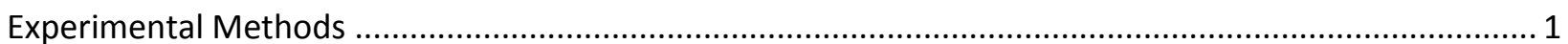

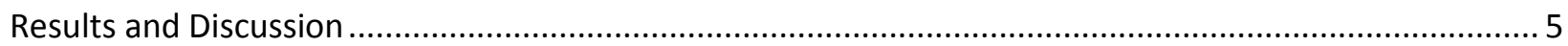

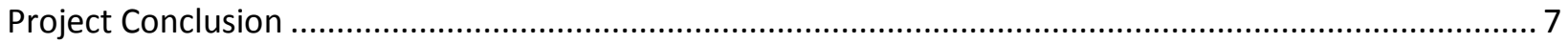




\section{Executive Summary}

This report represents the final technical report for this Project.

This Project was scoped to evaluate the durability of a state-of-the-art hydrogen internal combustion engine (HICE) design in both field and laboratory applications. The project had four (4) defined tasks:

- $\quad$ Task One (1) - Laboratory Accelerated Durability Testing

- Task Two (2) - Field Testing in Diverse Fleets

- Task Three (3) - Assessment of Durability Risks and Recommendations For Risk Reduction

- $\quad$ Task Four (4) - Reporting

Task 1 involved building an HICE unit which was operated on an engine dynamometer for 1000 hours. The operating scheme for 700 of these hours were designed around various dynamometer schedules designed to evaluate engine lubrication and related bearing and wear surface durability. The remaining 300 hours were performed by cycling between max power and max torque. A teardown of this dynamometer engine revealed no unusual wear. Metallurgical analysis showed no unusual material properties.

Task 2 involved operating eight HICE-equipped pickup trucks to an average of 24,000 miles per vehicle. The vehicles operated for nearly three years to achieve this goal. During this operating period, regular maintenance was performed including oil changes, spark plug replacement and fuel injector replacement. Two trucks were sent to Argonne National Laboratory on several occasions during this operating period to measure emissions performance. Used oil samples were captured and sent to two labs for analysis.

The results from Task 2 indicate that the vehicles provide reliable operation during this period. Emissions remained at low levels for the entire period. Oil analysis shows little indication of excessive wear in these engines.

Task 3 involved disassembling the engines and performing material analyses on engine components. A gasoline-fueled engine of similar design was procured from a recycling yard so that comparisons could be made to the HICE units. The disassembled engines (including the 
gasoline-fueled unit) showed little sign of wear, although somewhat heavy deposits of carbon were present on the intake and exhaust valve faces and piston crowns for the HICE units. These deposits are expected to be a result of excessive engine oil blow-by resulting from the high intake charge pressures. Metallurgical analyses of certain engine parts provided little indication in the way of adverse affects on the engine materials. The heavy deposits skewed the results from certain tests so the samples were cleaned and those tests repeated. An impact test was conducted on intake valves and those from the HICE units showed clear signs of brittle fracture while those from the gasoline-fueled unit fractured in a ductile fashion. It was determined that the brittle fracture was a result of hydrogen embrittlement.

Task 4 comprehended the reporting requirements for this Project

The Project was successful in meeting its goal. The engines validated that HICE technology can provide reliable operation. The project also provided insight into areas that require additional research in order to improve this technology:

- Water control in engine oil

- Sparkplug corrosion

- Fuel injector durability

- Oil blow-by resulting from boosted intake pressures

- Direct injection as a possible alternative to supercharging

- Material selection - particularly for valves and valve seats to reduce wear and prevent embrittlement

The Project met its goals. HICE technology was demonstrated in several operating modes and proved to provide reliable operation, particularly with off-the-shelf components. The data show that this technology can provide reliably-low emissions performance through careful engine calibration and without exhaust after-treatment. Through this work, specific areas and components were identified that would benefit from additional research to further improve HICE durability. 


\section{Experimental Methods}

The current project was intended and designed to evaluate and demonstrate the durability of hydrogen internal combustion engines (HICE) so as to understand the ability of this technology to provide a "bridge" between gasoline internal combustion engines and hydrogen fuel cell technology.

The objective of the project was stated as:

This program of work will evaluate the durability of a state-of-the-art hydrogen internal combustion engine (HICE) design in both field and laboratory applications. Results of the work will be compared to current gasoline internal combustion engine standards and recommendations to reduce durability risk factors developed.

The project was divided into four tasks as follows

- Task One (1) - Laboratory Accelerated Durability Testing

- Task Two (2) - Field Testing in Diverse Fleets

- Task Three (3) - Assessment of Durability Risks and Recommendations For Risk Reduction

- $\quad$ Task Four - Reporting

Task one involved building an HICE and operating it on a dynamometer for 1,000 hours of nearcontinuous use. Roush Industries was contracted to build an engine as per an earlier design and operate the engine in one of their dynamometer cells specially outfitted for use with hydrogen fuel. The engine was operated using the schedule presented in Table 1. 
Table 1--Engine Dynamometer Schedule

\begin{tabular}{|c|c|c|}
\hline Test Type/ Cycles conducted & $\begin{array}{l}\text { Duration } \\
\text { (hours) }\end{array}$ & Status \\
\hline \multicolumn{3}{|l|}{ Modified VIA Test } \\
\hline 20 cycles; engine break-in & 70 & Complete \\
\hline \multicolumn{3}{|l|}{ Performance Map } \\
\hline 1 cycle; Baseline engine performance & 3 & Complete \\
\hline \multicolumn{3}{|l|}{ Modified Sludge Test } \\
\hline 54 cycles; Simulates stop \& go driving for engine break-in & 216 & Complete \\
\hline \multicolumn{3}{|l|}{ Modified Sequence IIIF } \\
\hline $\begin{array}{l}10 \text { cycles: Simulates high speed and load service, } \\
\text { accelerating piston deposits }\end{array}$ & 70 & Complete \\
\hline \multicolumn{3}{|l|}{ Modified L38 Test } \\
\hline $\begin{array}{l}20 \text { cycles; Simulates high speed service, accelerating } \\
\text { bearing corrosion and wear }\end{array}$ & 70 & Complete \\
\hline \multicolumn{3}{|l|}{ Modified VE Test } \\
\hline 72 cycles: Simulates urban service, accelerating wear & 288 & Complete \\
\hline \multicolumn{3}{|l|}{ Modified III GA Test } \\
\hline $\begin{array}{l}30 \text { cycles: Simulates high temperature conditions, } \\
\text { accelerating valve wear }\end{array}$ & 105 & Complete \\
\hline \multicolumn{3}{|l|}{ Modified P \& G Test } \\
\hline $\begin{array}{l}50 \text { cycles: Operates engine at maximum torque, simulating } \\
100,000 \text { miles of engine operation, testing valves, pistons } \\
\text { rings, and valve seats under high stress conditions }\end{array}$ & 175 & Complete \\
\hline \multirow[t]{2}{*}{$\begin{array}{l}\text { Performance Map } \\
1 \text { cycle; Baseline engine performance after accelerated } \\
\text { aging }\end{array}$} & 3 & Complete \\
\hline & 1,000 & \\
\hline
\end{tabular}

At the conclusion of task one, the engine was disassembled, inspected for irregularities and certain components were sent to a material analysis lab.

Task two involved building eight (8) vehicles using HICE technology and operating them for an average of 24,000 miles each over a two-year period. During this period, two trucks were scheduled to conduct regular emissions and performance tests to monitor engine performance. 
Additionally, engine oil was analyzed at every change to determine what components may suffer from accelerated wear while operating with hydrogen fuel.

Roush Industries converted eight GMC Sierra 1500HD pickup trucks with HICE engines of identical design to the unit built for task one along with hydrogen storage cylinders sufficient to provide 150 miles of city range and 200 miles of highway range. Figure 1 shows one of the eight HICE trucks in Vancouver, BC.

\section{Figure 1--HICE Truck}

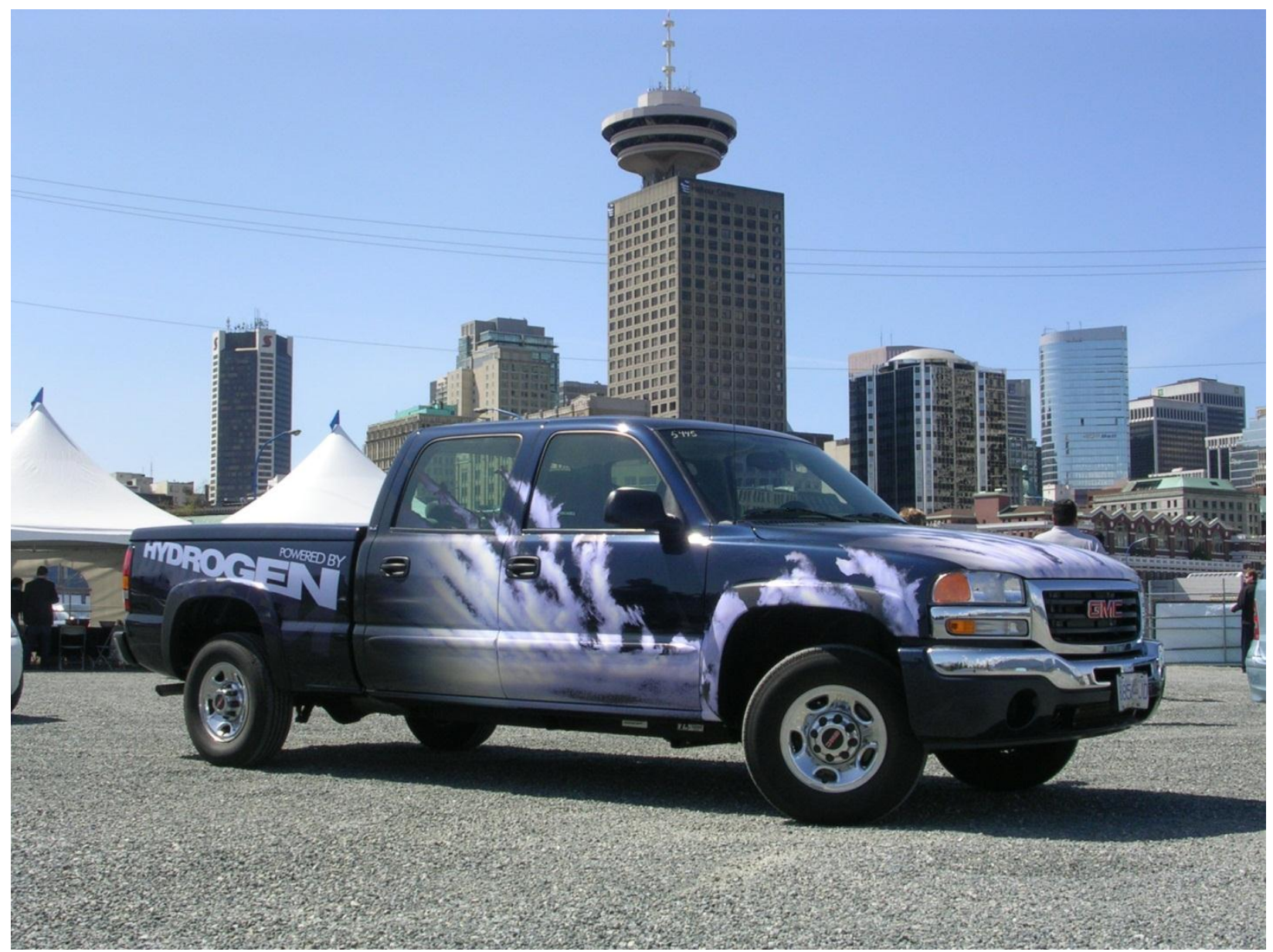

These trucks were operated in Vancouver, BC by Powertech Labs and Sacre-Davey Engineering who were operating a large-scale project to reclaim waste hydrogen for use as a motor fuel. By joining with this project, this DOE-funded project was able to provide the extraordinary quantities of fuel required for the two-year operating period at no cost to the project. 
The trucks were operated by a variety of vehicle operators to allow for a wide variety of driving styles to better explore the durability of HICE technology. Table 2 provides a list of the vehicle operators and the miles accumulated for each vehicle.

Table 2--HICE Vehicle Assignments

\begin{tabular}{|c|c|c|c|c|}
\hline & VIN \# & $\begin{array}{c}\text { Fleet Vehicle } \\
\text { Number }\end{array}$ & $\begin{array}{l}\text { Mileage }^{12}, \\
\quad(\mathbf{k m})\end{array}$ & Location \\
\hline 1 & 1GTGC13U96F160975 & 5565 & 34598 & Air Liquide \\
\hline 2 & 1GTGC13U26F162843 & 5561 & 40313 & Powertech Labs \\
\hline 3 & 1GTGC13U56F161945 & 5566 & 29358 & Arc'teryx \\
\hline 4 & 1GTGC13U56F161319 & 5564 & 22923 & City of North Vancouver \\
\hline 5 & 1GTGC13U86F161292 & 5562 & 28028 & Port Authority of Vancouver \\
\hline 6 & 1GTGC13U06F160945 & 5567 & 33713 & Powertech Labs \\
\hline 7 & 1GTGC13U66F155684 & 5563 & 34541 & Transport Canada $^{3}$ \\
\hline 8 & 1GTGC13U15F960409 & 5445 & 35963 & Sacré-Davey \\
\hline & & & 32430 & $F L E E T A V E R A G E^{4}(\mathrm{~km})$ \\
\hline
\end{tabular}

Argonne National Laboratory ANL was contracted to perform emissions tests on the vehicles at six-month intervals during 2007 and 2008 and then once during 2009 (due to budget limitations and consistent emissions performance). Appendix A presents a summary of the emissions tests for both HICE trucks tested at ANL.

Powertech Labs performed regular maintenance on the vehicles including oil changes as well as spark plug replacement (every six months) and fuel injector replacement (approximately yearly) required to keep the engines running properly. Additionally, used oil samples were captured during the regular oil changes and sent to two separate analysis labs to determine the level of contaminants which is an indication of wear performance of engine components. Appendix B contains a summary of the results from oil analysis during task two.

\footnotetext{
${ }^{1}$ Cumulative mileage accumulated to date since project initiation.

${ }^{2}$ Numbers reported for the previous period were in error. Odometer readings were reported instead of net km accumulated since project initiation

${ }^{3}$ Returned to Sacré-Davey during this reporting period

${ }^{4}$ Fleet Average target is $38624 \mathrm{~km}$
} 
At the conclusion of the operating period, two trucks were sent to Roush Industries where their engines were removed, disassembled and measured to determine if any significant wear was evident or if there were any additional signs of stress or failure that could be attributable to operation on hydrogen fuel. Following the disassembly, a selection of engine components from each engine was sent to a material analysis lab. A series of tests were conducted to determine elemental constituents, material structure and material properties. The goal of the analysis was to determine if operation with hydrogen fuel had adversely changed the material properties and to look for-in particular-signs of hydrogen embrittlement.

Task four covered reporting for the project. Quarterly status reports were submitted along with the present final technical/scientific report.

\section{Results and Discussion}

The HICE operated on an engine dynamometer for 1,000 hours of operation with no failures other than corroded spark plugs and a fuel injector failure. During the engine disassembly, all components were in exceptionally good condition with the exception of intake and exhaust valves. Valve recession was prevalent in both intake and exhaust valves with the intake valves showing the most severe recession measurements. Furthermore, an unusual brownish-red deposit was present on all components inside the combustion chamber as well as exhaust ports and manifolds. Metallographic analyses were conducted on the cylinder walls, intake and exhaust valves and seats and a portion of the cylinder block. No unusual findings were found during these analyses.

The eight (8) HICE trucks operated in Vancouver with little more than regular maintenance required to keep them operating. Spark plugs were discovered to have a six-month life in these engines. Fuel injectors lasted approximately one year for the early designs but there were indications that later revisions of this design would provide longer life. The "stuck open" failure mode resulted in flame jets burning through intake gaskets and into wire harnesses - not severe enough to cause the vehicle to stop operating. A third operating year was added to the project in 
an attempt to achieve the mileage goal (24,000 miles average per vehicle) due to the fact that some vehicle operators either used their vehicle very sporadically or used it for very short trips.

Oil changes were conducted regularly and used oil samples from each vehicle were sent to two separate labs for analysis. In general, these analyses showed few signs of excessive wear in these engines. However, several samples across the fleer and across the entire fleet operation period exhibited excess water in the oil samples. This was determined to be the result of frequent engine stop/start events that generated excess combustion water while not allowing the engine to get up to operating temperature and evaporate the water out of the oil sump.

Two of the nine engines were disassembled following the three-year operation period. In general, both engines showed little sign of wear or stress. The tops of the pistons, valve faces and intake and exhaust ports showed heavy, black deposits. These deposits were likely a result of pulling oil into the combustion chambers through the positive crankcase ventilation system as a result of high boost pressures in the intake charge. Valve recession and general wear were evident in both engines. A gasoline engine was procured at the request of the DOE Project manager to provide a comparison point between hydrogen and gasoline fuel. An engine having the same alternative-fuel cylinder heads was sought and procured for this project. It was disassembled in the same fashion. Very little wear was apparent and the valves and combustion chambers were much cleaner. The valve exhibited little signs of wear.

As with the dynamometer engine, metallographic analyses were conducted on cylinder walls and intake and exhaust valves and seats. Initial results from these analyses were inconclusive because of the heavy deposits, particularly on the valves. These samples were cleaned in an ultrasonic petroleum bath (for Electron Spectroscopy analyses) or with antimony inhibited HCL (for Scanning Electron Microscope / Energy Dispersive Spectroscopy analyses) as an attempt to better evaluate the underlying metal material (some amount of the deposits remained after cleaning, but there was concern that more aggressive cleaning would alter the metallographic tests.

A second series of ESCA and SEM/EDS tests were conducted which yielded much better results in terms of measuring the properties of the sample material. Whereas the initial tests showed greatly reduced percentages of iron and very high percentages of oxygen and carbon, the revised 
tests showed that a very high percentage of iron was present. However, the tests helped determine that the composition of the valves from the gasoline engine was different than that for the two HICE units. It is likely that the gasoline engine that was sourced from an automotive recycler did not have the special KL5 (alternative fuel) cylinder heads that were used with the HICE units during their initial assembly.

The final test in the series was an impact test to help understand if the physical properties of the materials in the HICE units were different than those for the gasoline engine. In fact, the results were quite different. The valve samples used for these impact tests showed brittle failure for the HICE samples, while those from the gasoline engine demonstrated ductile fracture. The metallurgical specialists who reviewed these tests results believe that the ductile failure is a result of hydrogen embrittlement.

\section{Project Conclusion}

The objective of this Project was to evaluate the durability of a state-of-the-art hydrogen internal combustion engine (HICE) design in both laboratory and field applications.

This objective was met with a combination of dynamometer operation of an HICE unit and onroad operation of a series of nine GM full-sized pickup trucks equipped with HICE units of identical construction to the dynamometer engine.

Both the dynamometer engine and on-road operation trucks demonstrated the ability of a hydrogen-fueled internal combustion engine to provide reliable service without significant component failure. The primary reason for this is believed to be that the engine output was significantly lower than the output with gasoline fuel (200hp vs. $300 \mathrm{hp}$ ) and the fact that the base gasoline engine was designed to provide 100,000 miles (or more) of reliable service at those higher power levels. While material or component degradation may have taken place over time, any weaknesses that might have been present were still able to withstand the power and stress levels present in the HICE application.

Emissions tests demonstrated that HICE technology can provide significant emissions benefits compared to gasoline or even natural gas engines. Without any after-combustion treatment (e.g., 
catalysts), these engines maintained extremely low levels of monitored pollutants throughout the period of this project. While this project was only able to evaluate these engines for 24,000 miles, there is no indication that emissions performance would significantly degrade with additional miles. A longer-term study — or one that had dedicated, three-shift per day drivers could provide additional data on emissions performance.

However, several issues were uncovered that could be the subjects of further study to further improve the longevity and reliability of HICE engines.

Engine Oil - the on-road durability task demonstrated that HICE engines have a propensity to create excess water which will migrate into the engine oil sump. If the engine is not allowed to reach full operating temperature on a regular basis, this water does not have an opportunity to evaporate out of the oil mixture which compromises the ability of the oil to provide sufficient lubrication to the engine parts. This issue may be overcome through engine management causing the engine to run hotter combustion temperatures to allow for faster warm-ups, operation strategy that keeps the engine running until operating temperatures are reached, or some external device that circulates the engine oil through a heater.

Sparkplugs - both the dynamometer and on-road operation engines suffered from regular fouling of spark plugs. This is believed to be due to accelerated corrosion either due to the amount of water created during the combustion process, some interaction with hydrogen fuel or both. In the case of the on-road operating engines, the sparkplugs demonstrated a life of 6 months. Much beyond that and the sparkplugs began to foul, leading to misfires. The solution would be a sparkplug specifically designed with corrosion resistant materials (e.g., stainless steel). Similar sparkplugs are used in marine applications, but none were available for this particular engine and development time and costs were beyond the scope of this project.

Fuel Injectors - these HICE engines used a port injection design where injectors are installed in the intake ports and pointed at the intake valve. The injectors themselves were supplied by Quantum Technologies and specifically designed for use with hydrogen fuel. Injectors have two failure modes: failing closed, in which case the respective cylinder provides no power; and failing open in which case hydrogen enters the intake tract in an unmetered fashion which can lead to ignition in the intake system or in the exhaust system. Both failures were experienced in 
the on-road operation engines. Two engines exhibited signs of hydrogen combustion that burned through intake manifold gaskets and ultimately compromised underhood wiring. At least one engine suffered a blown muffler due to excessive hydrogen in the exhaust system.

Two main issues present a challenge for injector design. First, hydrogen molecules are so small that it is difficult to design a valve system that can provide a total seal. Without a complete seal, it is difficult to accurately and repeatedly meter the fuel for proper engine operation. Second, hydrogen is typically a very dry fuel and provides no lubricity for the injector's internal moving parts. Currently, most hydrogen available at dispensing stations is extraordinarily clean to support the requirements of fuel cell vehicles. Experimentation with lesser grades of hydrogen, perhaps doped with small amounts of lubricating oil might prove useful. As it is, Quantum's early injectors proved to have a 12-month life. The third (and latest) generation of these injectors have proven reliable to-date and may provide longer life than previously experienced.

Superchargers - A supercharger was used on these engines in order to provide the quantity of air needed to achieve the desired power level using the very lean fuel-air mixtures required to achieve low emissions. Due to the increased intake air pressures used to achieve this air volume, excessive oil blow-by resulted and was the likely the predominant cause for the deposits found on the pistons and valves. While superchargers have been used successfully with production engines, they add cost and sap power from the engine. In one case, a supercharger drive coupling failed in the unit's gear drive which caused that engine to immediately stop working.

Turbocharging could be an alternative as it typically has much lower parasitic losses when compared to an engine-driven supercharger. However, turbochargers have higher initial cost (due to complexity of exhaust and intake air ducting), do not provided needed boost at low engine speeds and still have the issue of high intake air pressures with the resulting engine oil blow-by.

One alternative to supercharging might be direct fuel injection. This method utilizes an injector design that introduces fuel directly into the combustion chamber. With such a strategy, atmospheric pressure could be used to fill the cylinder with pure air and then inject hydrogen —at elevated pressures - during the compression stroke to achieve the desired fuel-air ratio. In order to accomplish this, a gaseous fuel injector would need to be designed that can adequately control 
fuel flow (e.g., leaks), handle the lack of fuel lubricity and survive the pressures and temperatures in the combustion chamber. A supercharge may still be needed to provide the quantity of air required to develop the target power numbers, but boost levels should be lower, reducing parasitic losses and engine blow-by.

One of the main concerns with using hydrogen in internal combustion is the issue of hydrogen embrittlement of engine components. The literature seems to indicate that high-strength steels are most susceptible to hydrogen embrittlement, but these materials are rarely used in an internal-combustion engine, particularly in the intake and combustion areas. The fact that the dynamometer engine and all nine on-road operation vehicles survived without engine component failure (outside those service components mentioned above), indicates that embritlement is not a primary concern. However, the material analysis conducted on the on-road operation engines indicated that the particular material used for the intake valves was susceptible to embrittlement (material failure may have occurred after a longer operation period than was afforded by this project). Additionally, the engine teardown analysis indicted that valve and seat wear was excessive, leading to valve recession in the cylinder heads) which will ultimately result in either complete valve failure or gradual reduction in engine efficiency due to poor sealing of the intake valve. Additional research is required to determine what materials are appropriate for use in valves and valve seats to provide the longevity required and expected of production passengervehicle engines today.

All aspects of the Statement of Project Objectives were achieved during this project. The data collected from the dynamometer engine, on-road operation maintenance and repair records, regular emissions tests, engine teardown and subsequent materials analysis provide the information required to direct further research and development project to further hydrogen internal combustion engine technology. 
APPENDIX A

EMISSIONS TESTING DATA 
HICE Durability Vehicle: 5445

Staveley Services Oil Analysis Results: TAN \& TBN

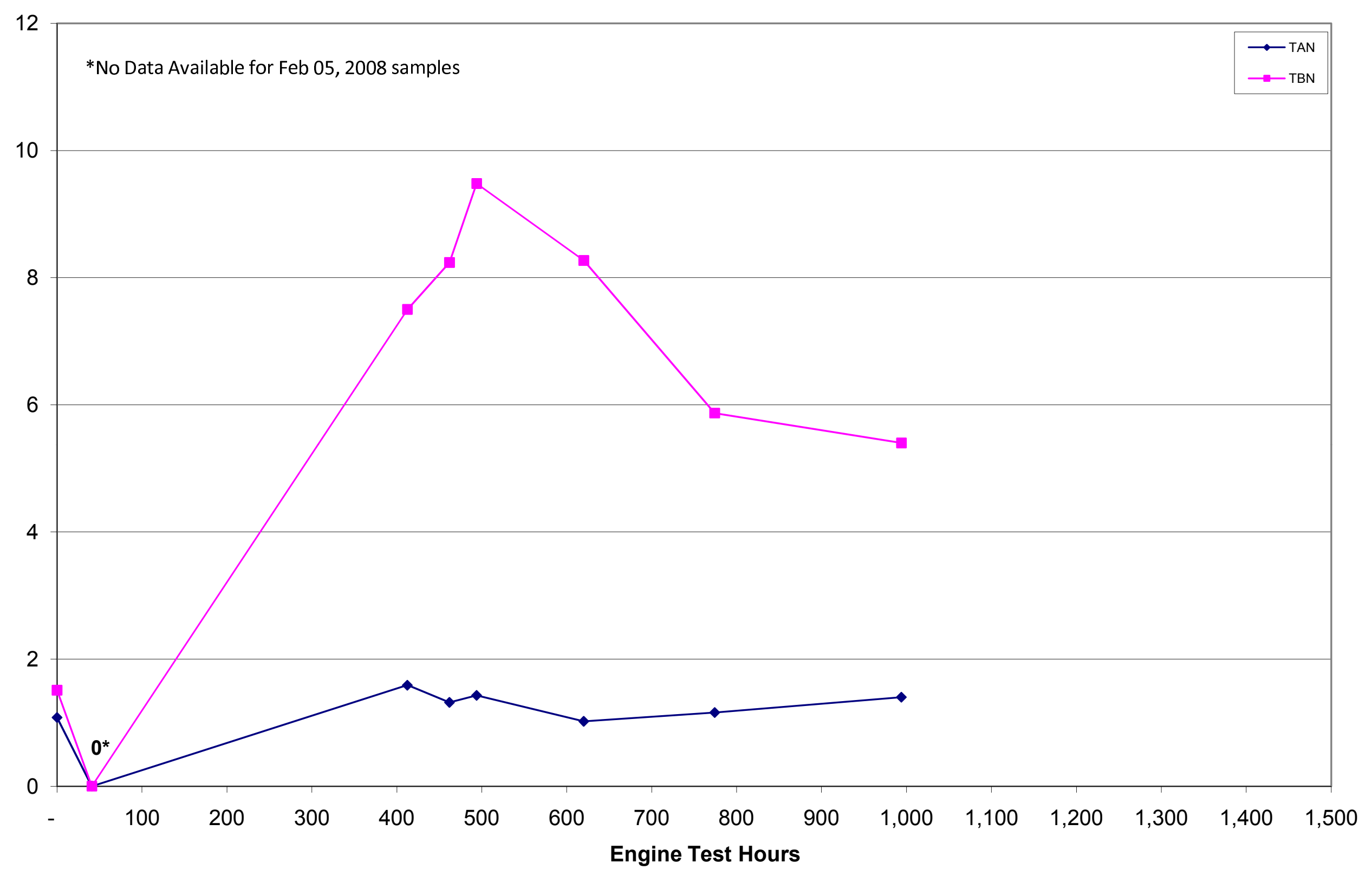


HICE Durability Vehicle: 5445

BTS Oil Analysis Results: TAN \& TBN

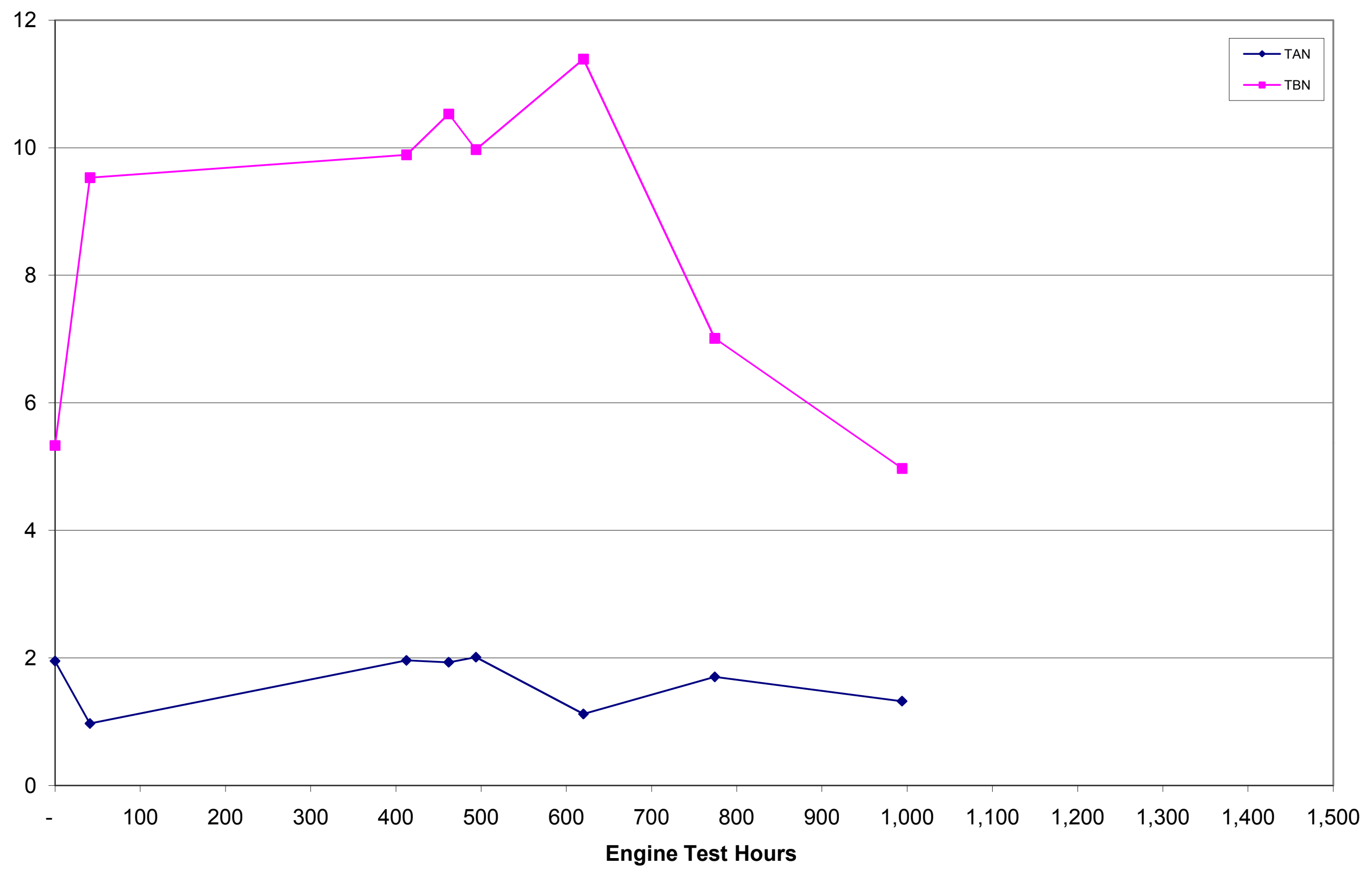


HICE Durability Vehicle: 5445

BTS Oil Analysis Results--Wear Metals

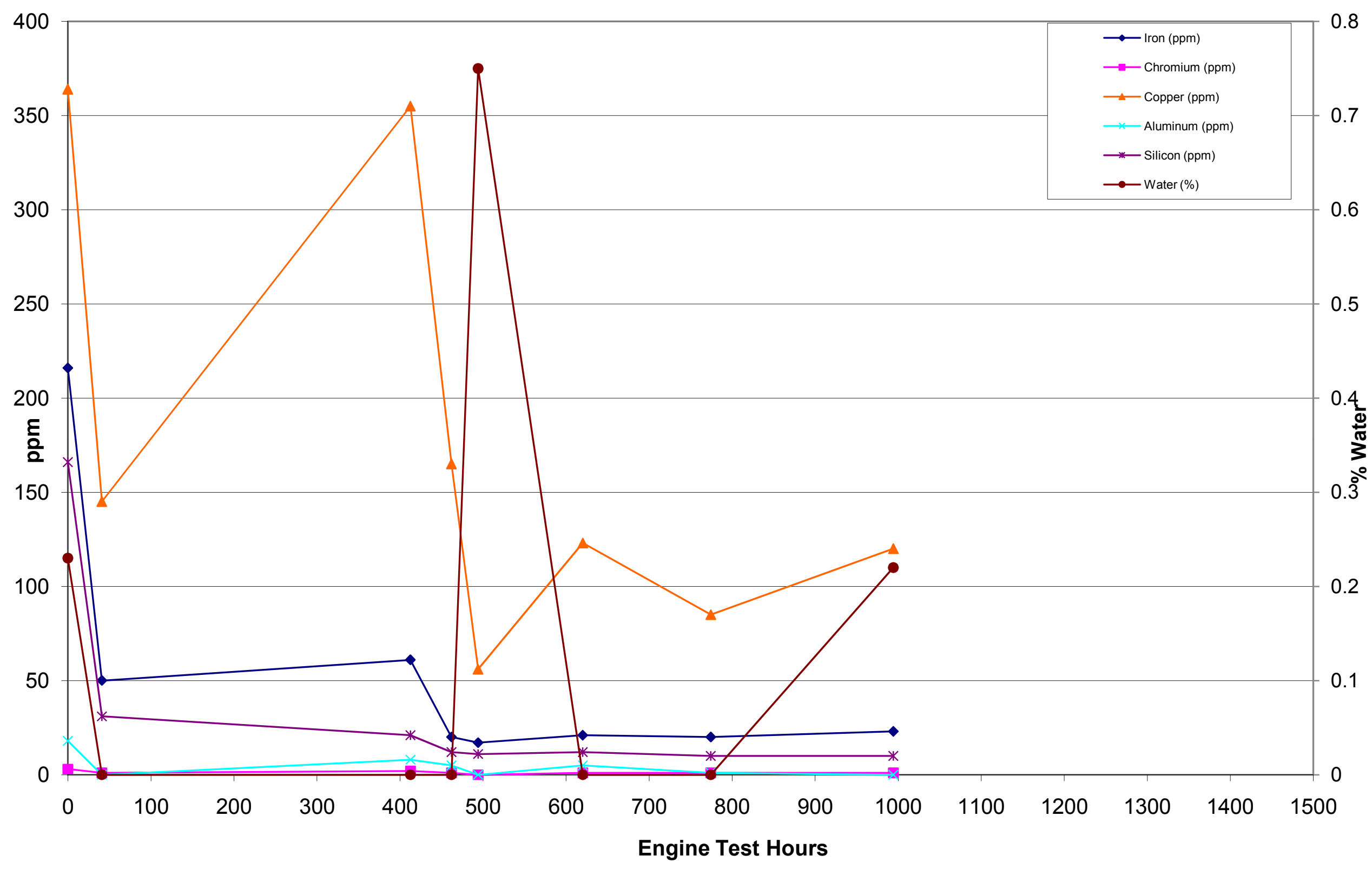


HICE Durability Vehicle: 5445

Staveley Services Oil Analysis Results--Wear Metals

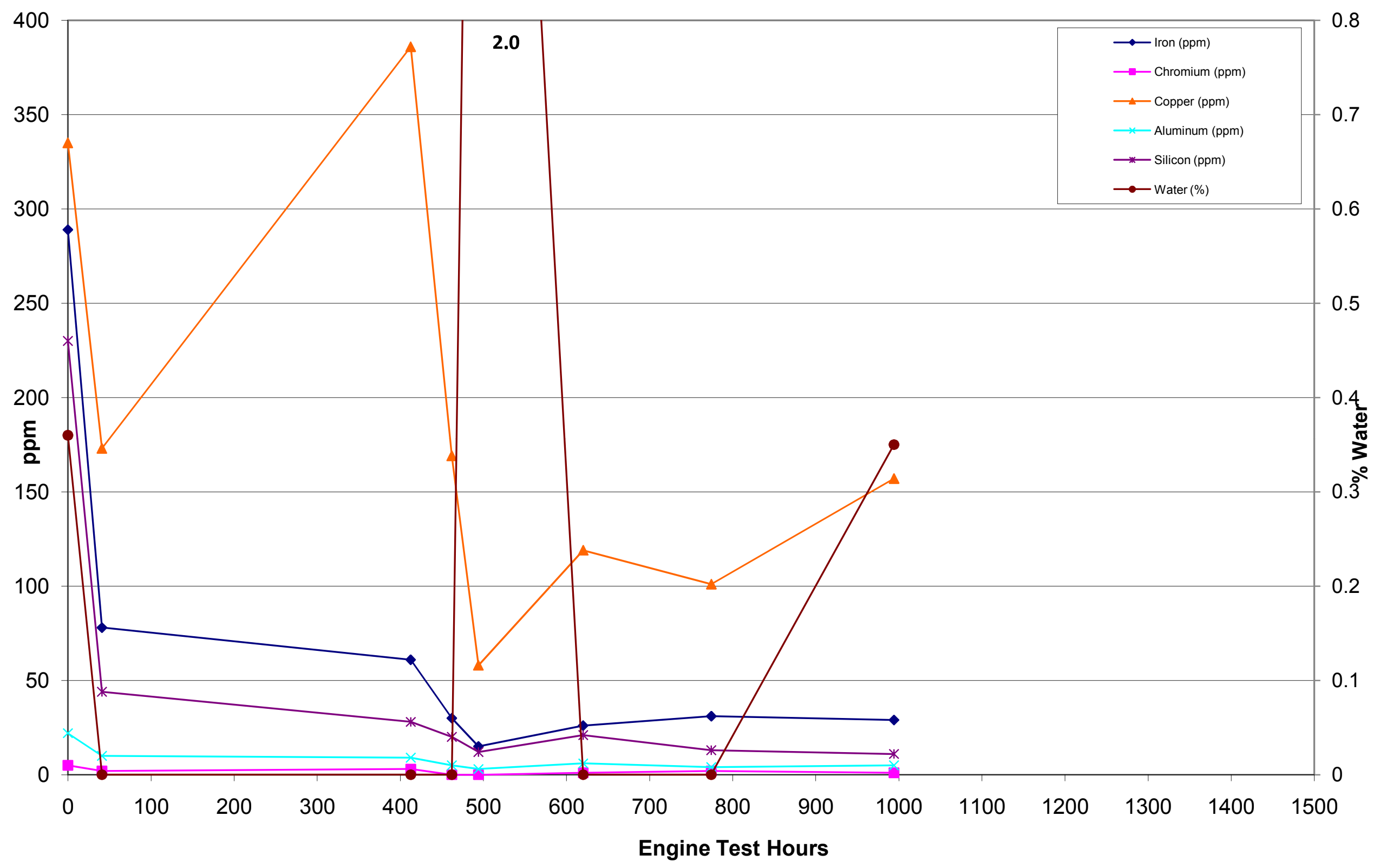


HICE Durability Vehicle: 5561

\section{Staveley Services Oil Analysis Results: TAN \& TBN}

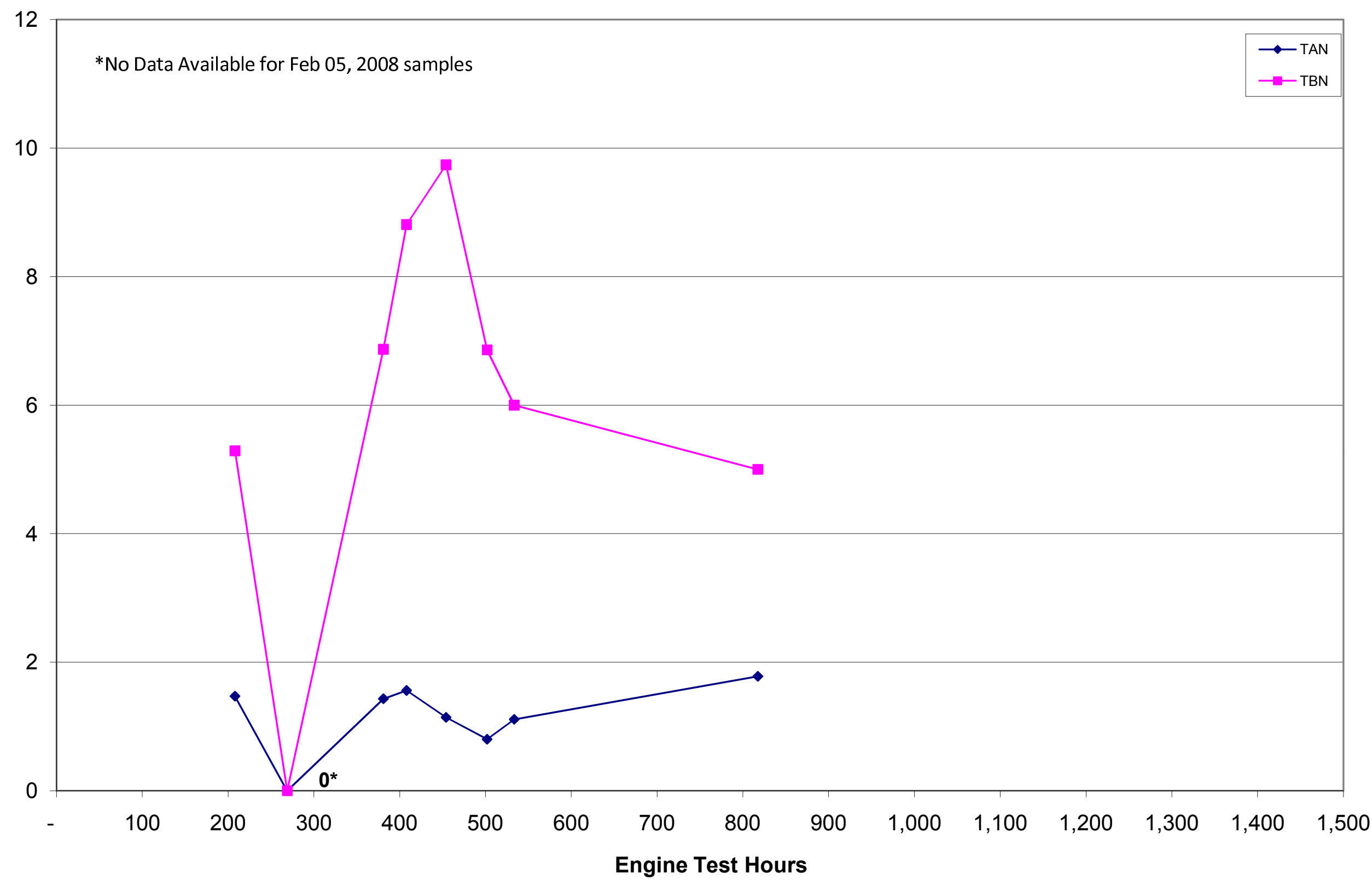


HICE Durability Vehicle: 5561

BTS Oil Analysis Results: TAN \& TBN

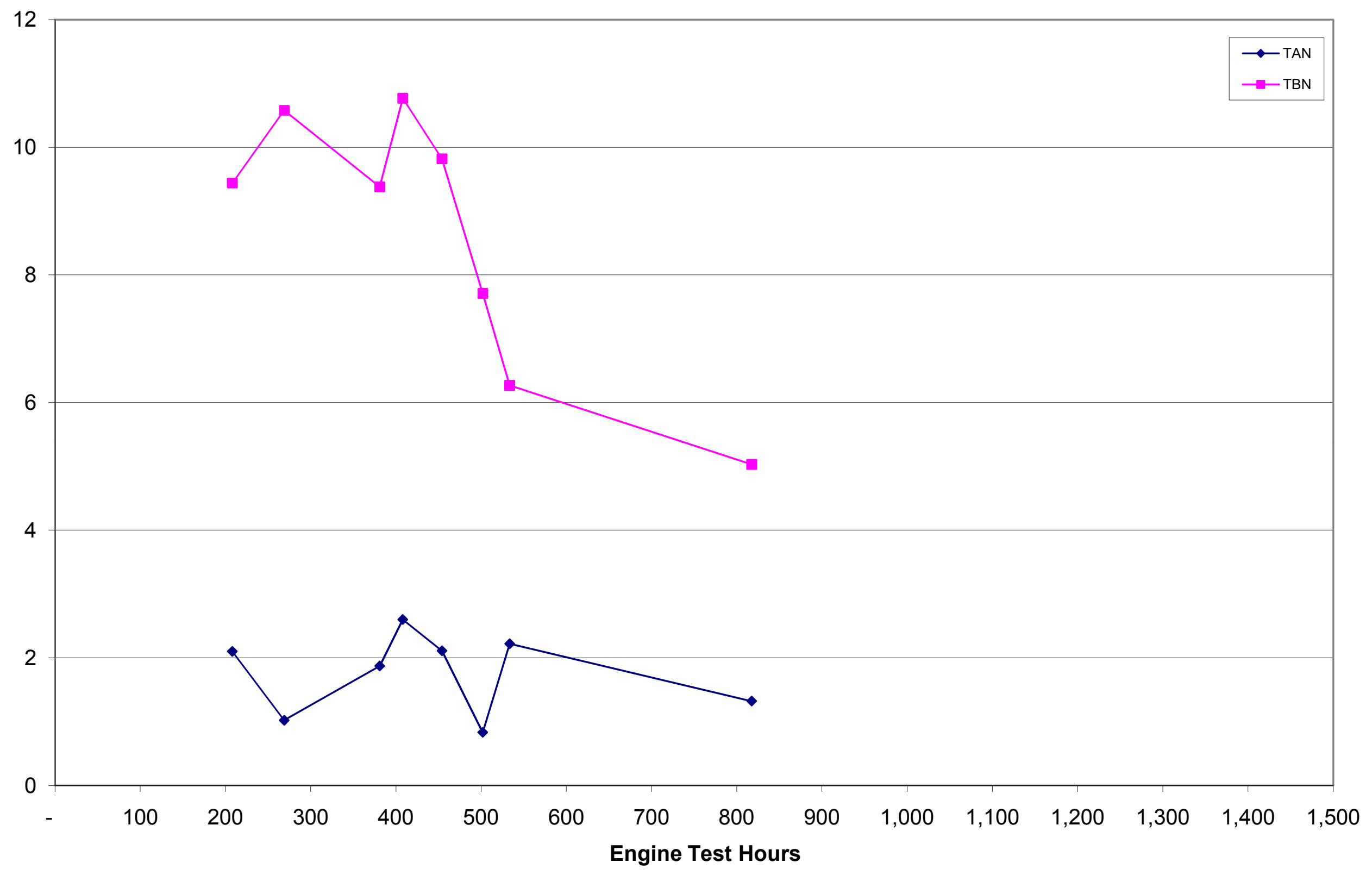


HICE Durability Vehicle: 5561

BTS Oil Analysis Results--Wear Metals

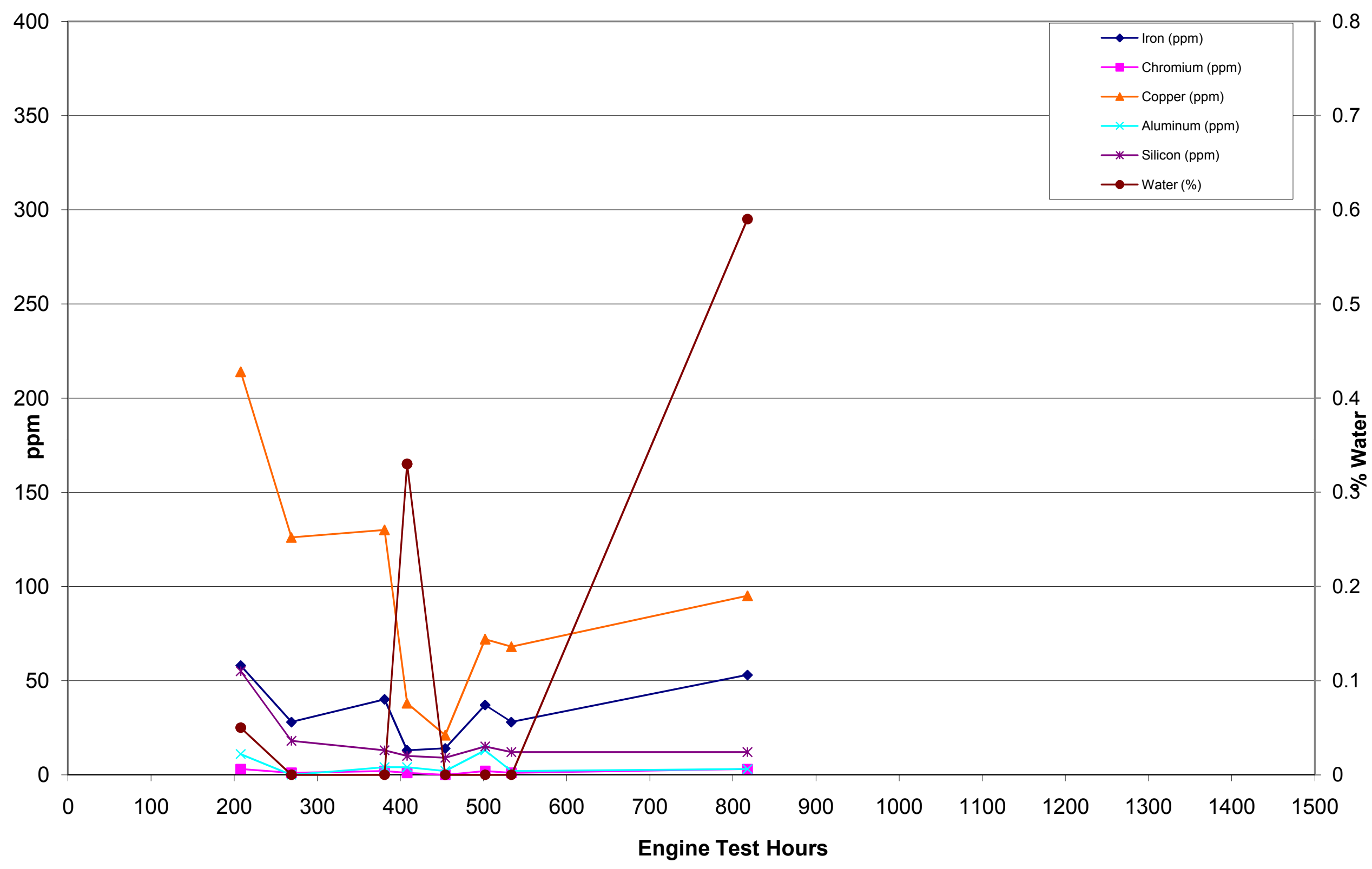


HICE Durability Vehicle: 5561

Staveley Services Oil Analysis Results--Wear Metals

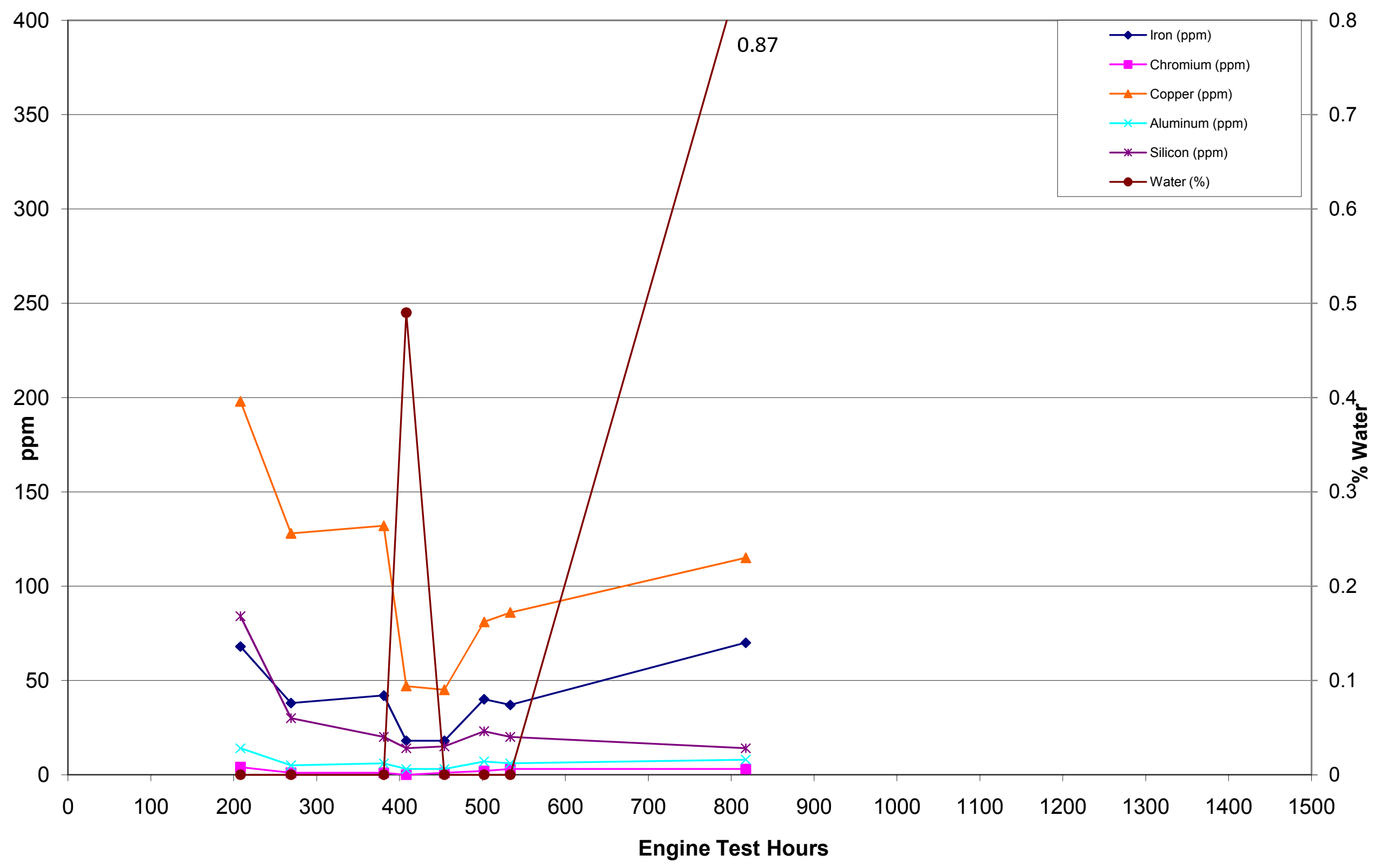


HICE Durability Vehicle: 5562

Staveley Services Oil Analysis Results: TAN \& TBN

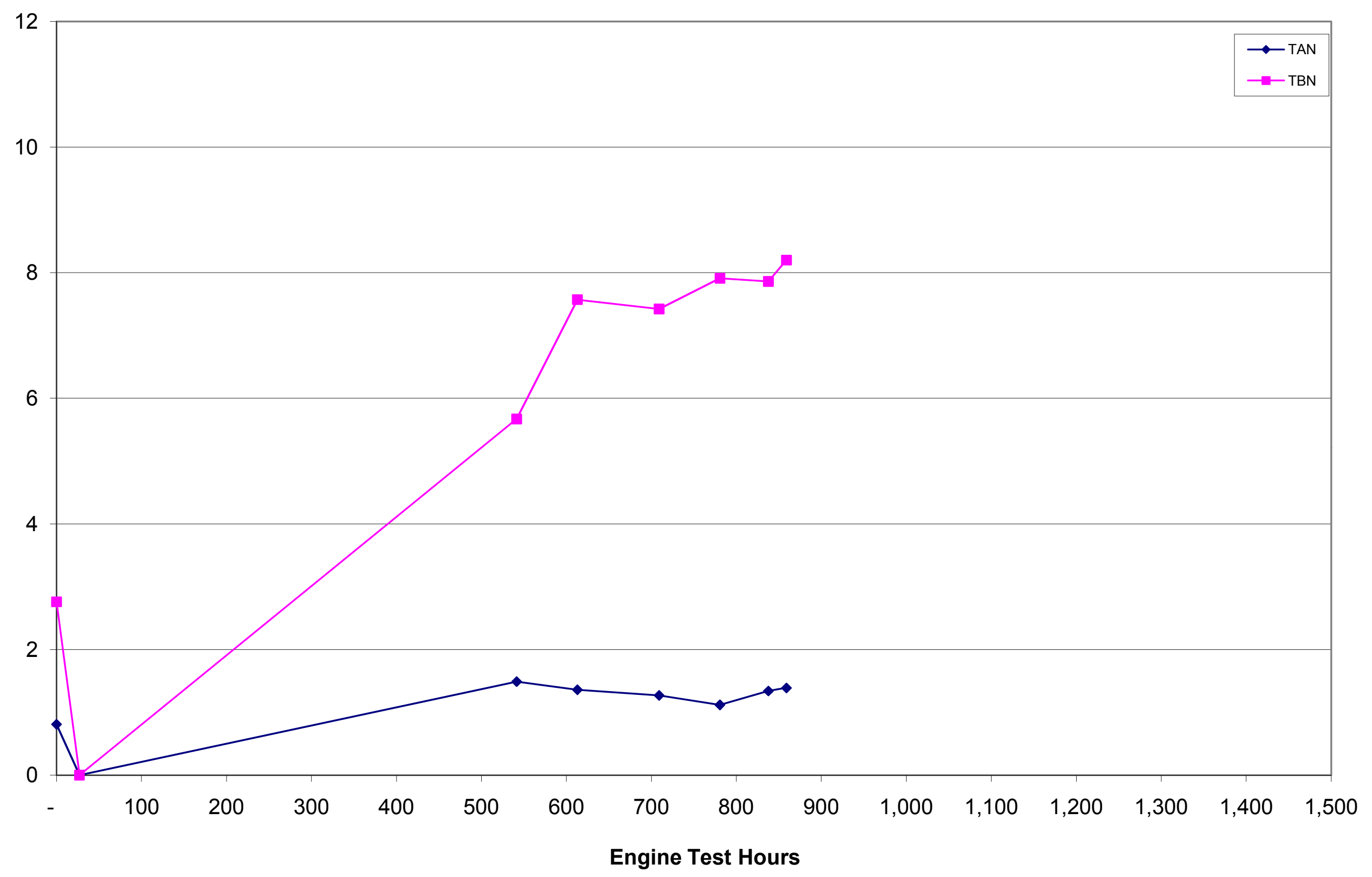


HICE Durability Vehicle: 5562

BTS Oil Analysis Results: TAN \& TBN

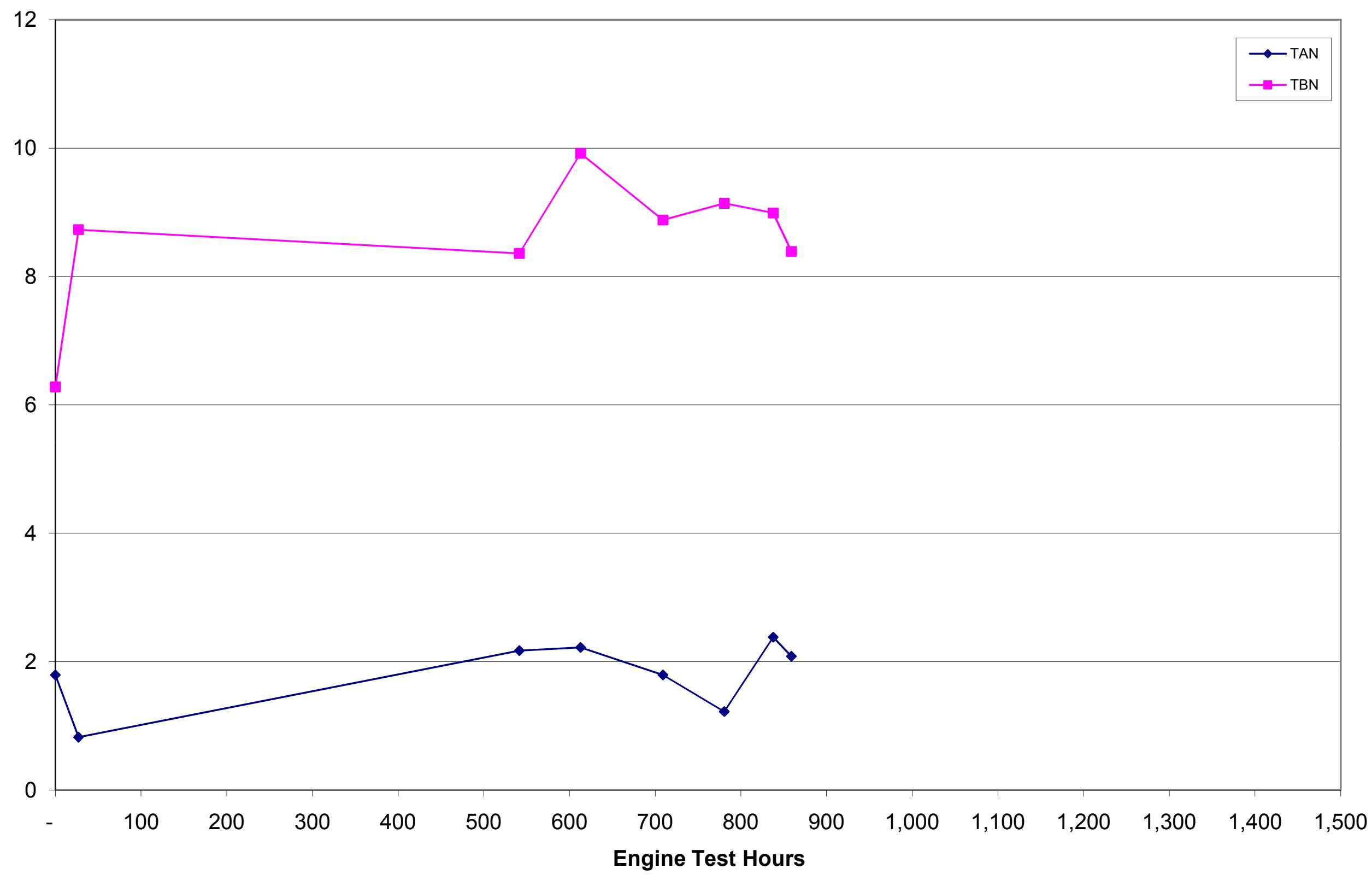


HICE Durability Vehicle: 5662

BTS Oil Analysis Results--Wear Metals

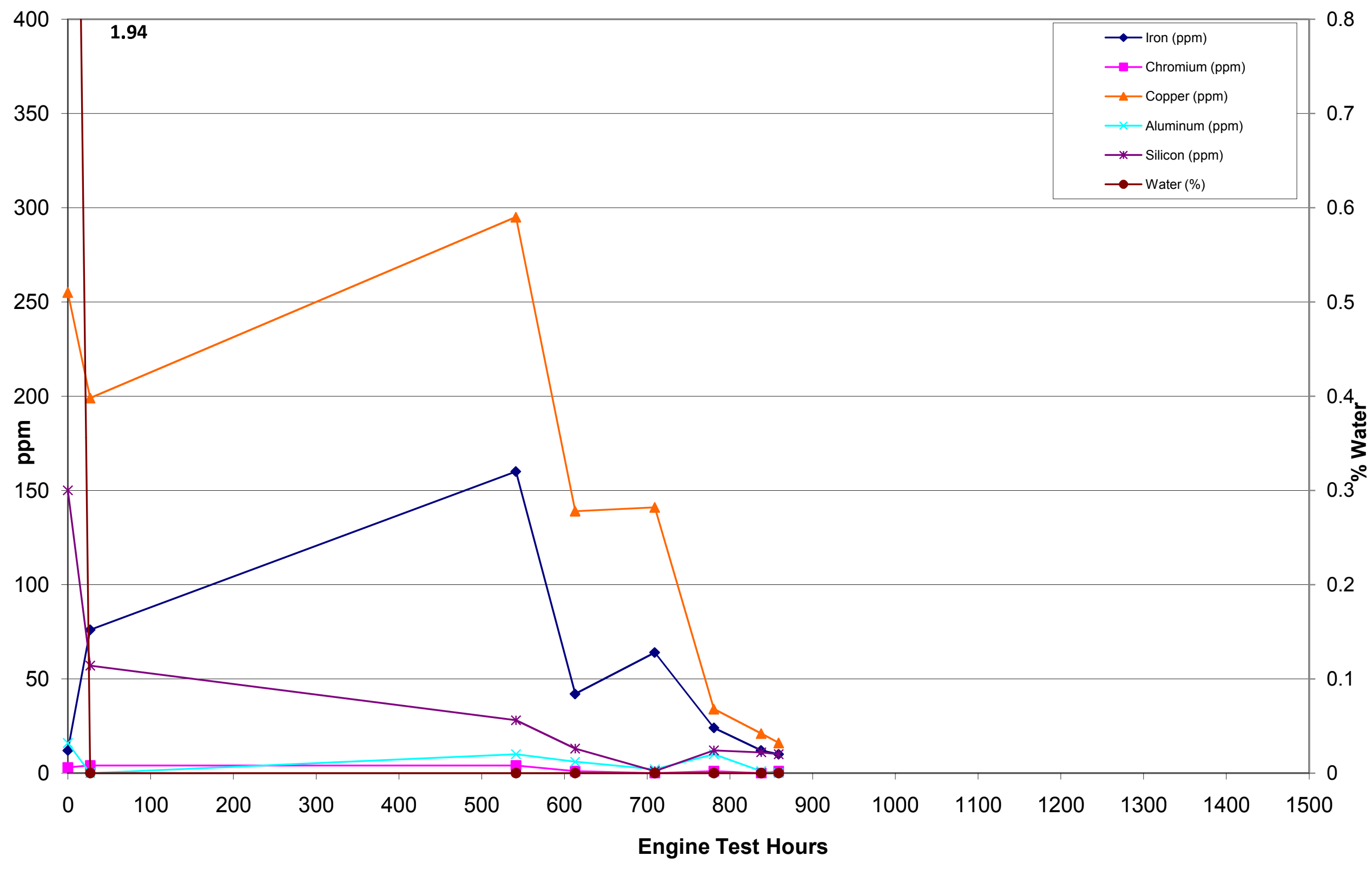


HICE Durability Vehicle: $\mathbf{5 5 6 2}$

Staveley Services Oil Analysis Results--Wear Metals

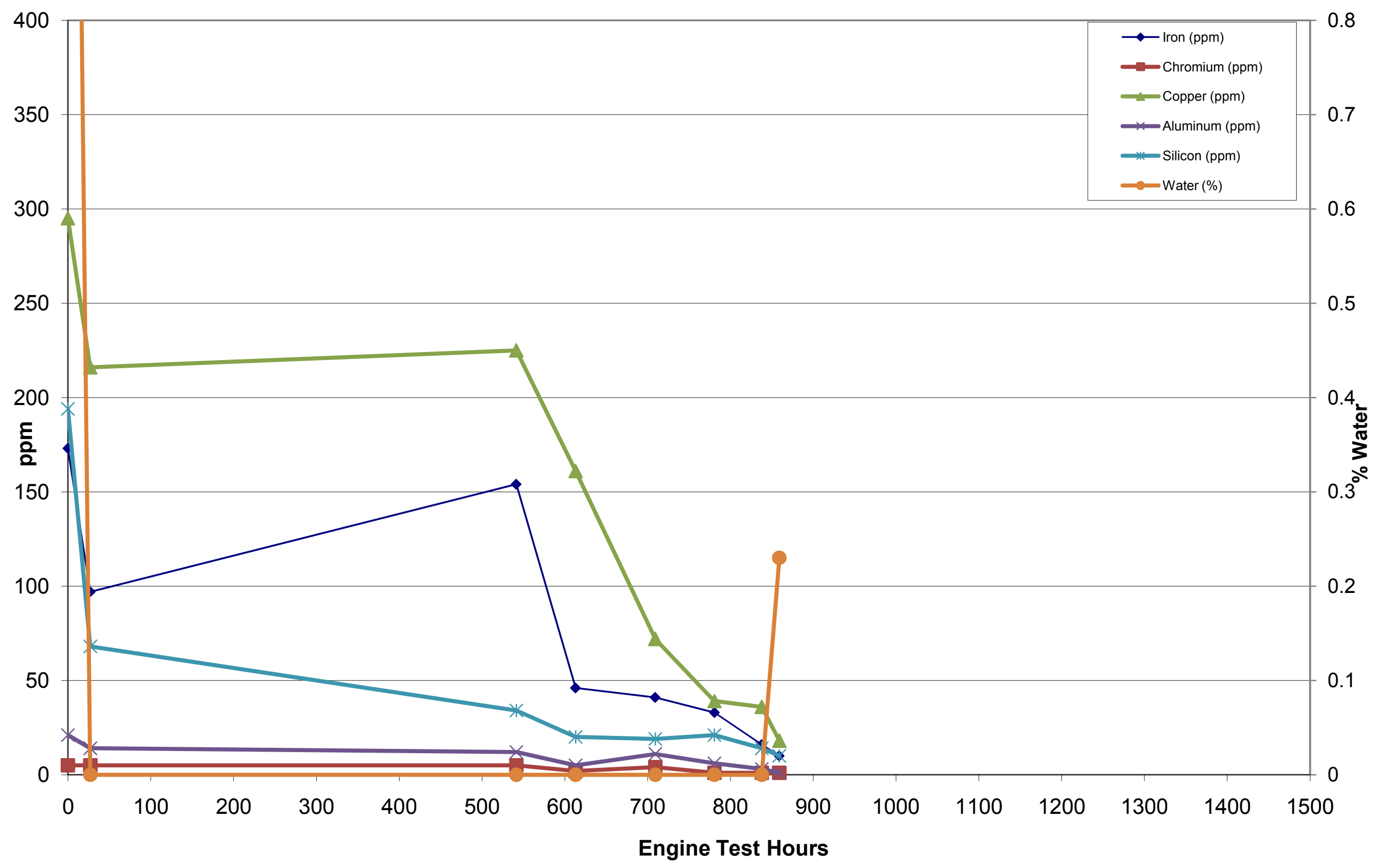


HICE Durability Vehicle: 5563

Staveley Services Oil Analysis Results: TAN \& TBN

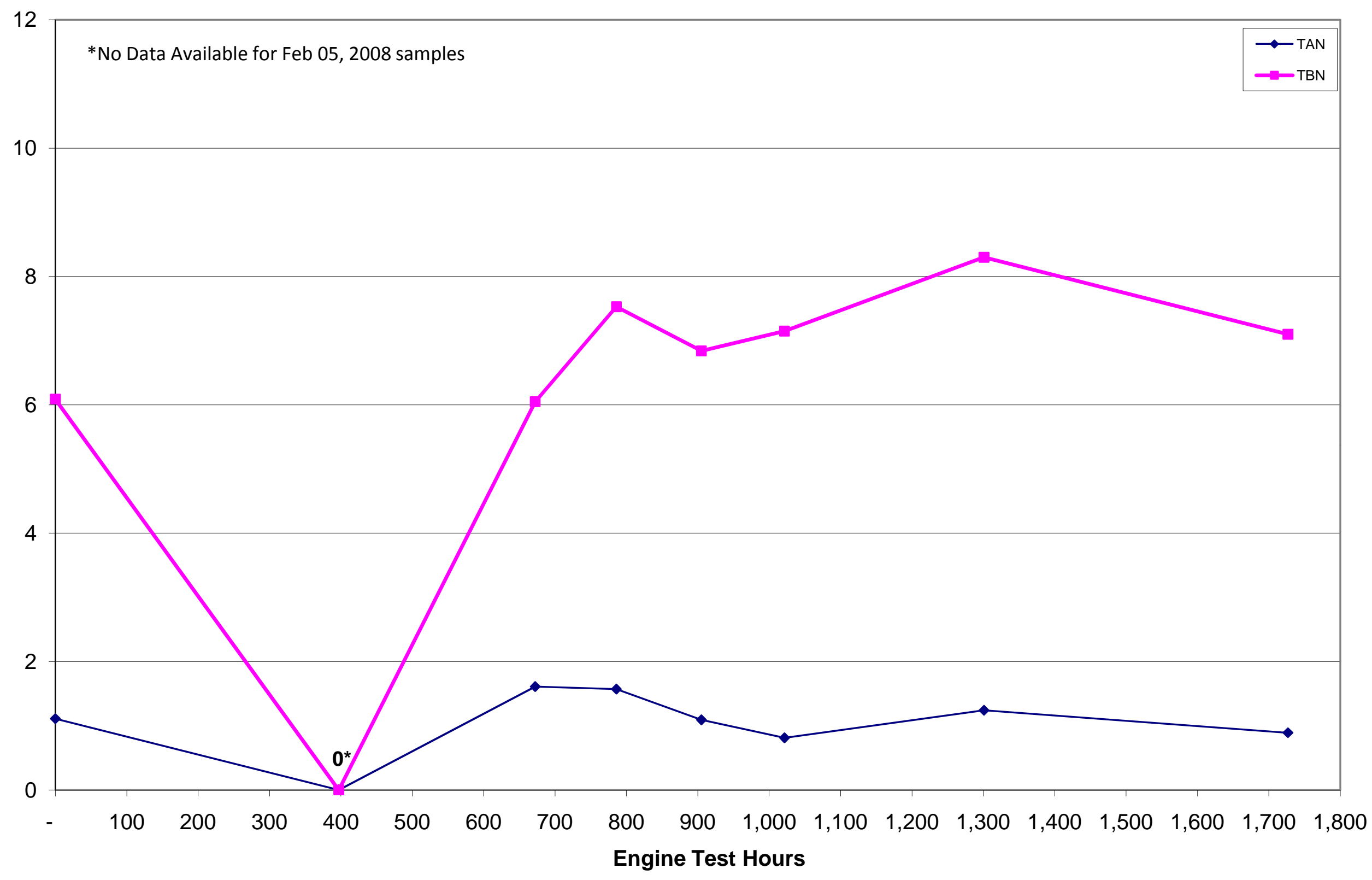


HICE Durability Vehicle: 5563

BTS Oil Analysis Results: TAN \& TBN

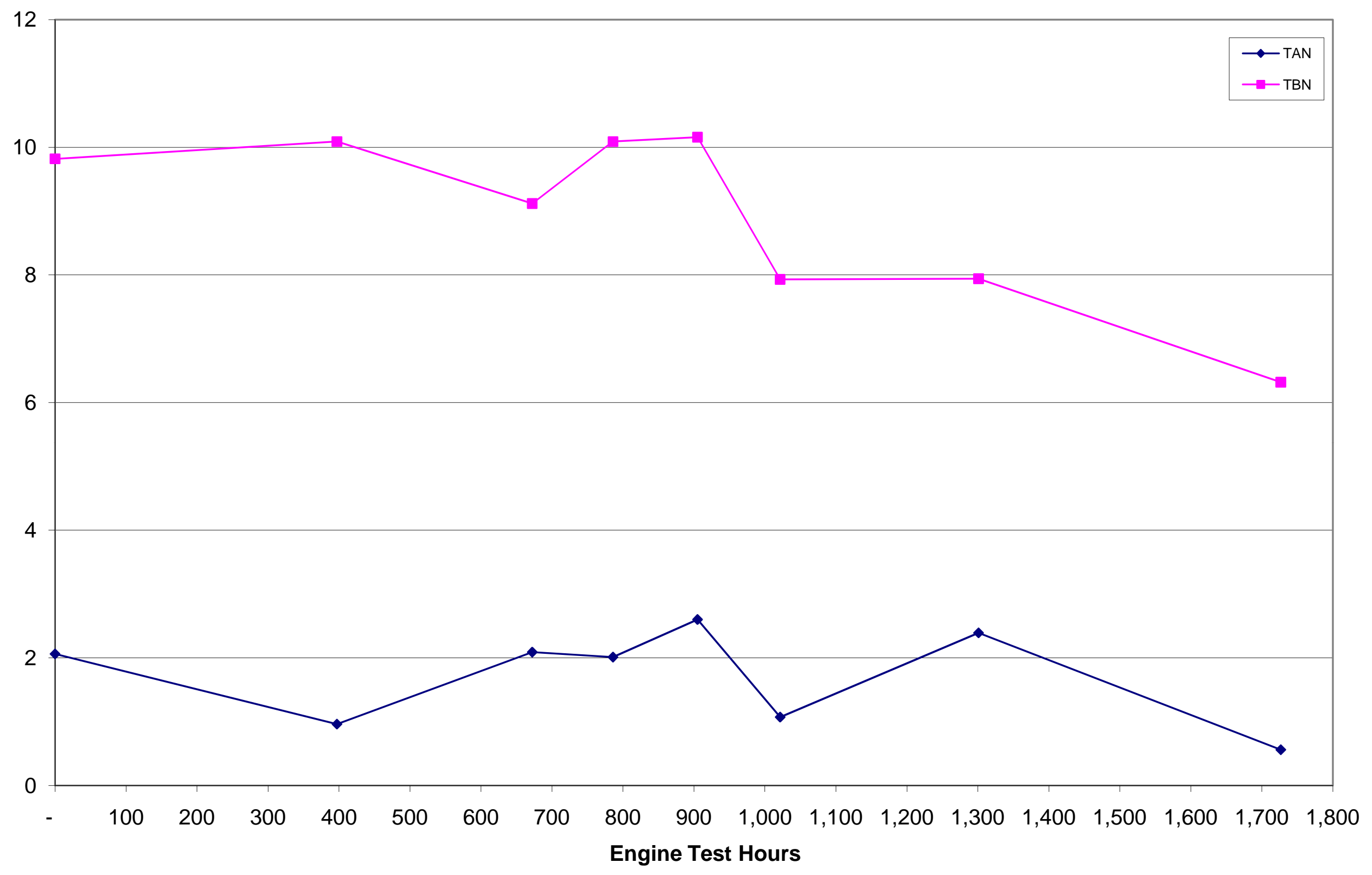


HICE Durability Vehicle: 5563

BTS Oil Analysis Results--Wear Metals

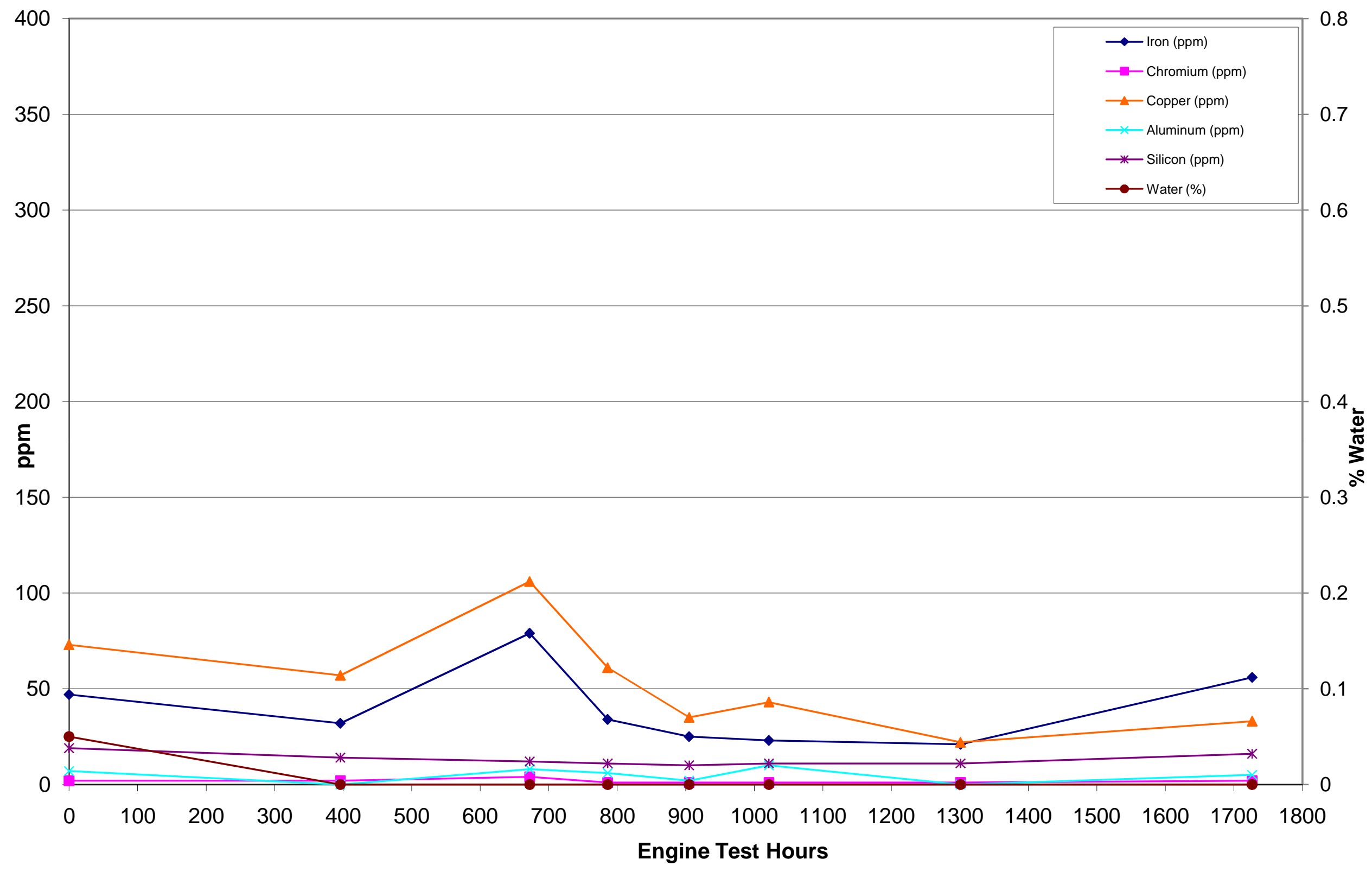


HICE Durability Vehicle: 5563

Staveley Services Oil Analysis Results--Wear Metals

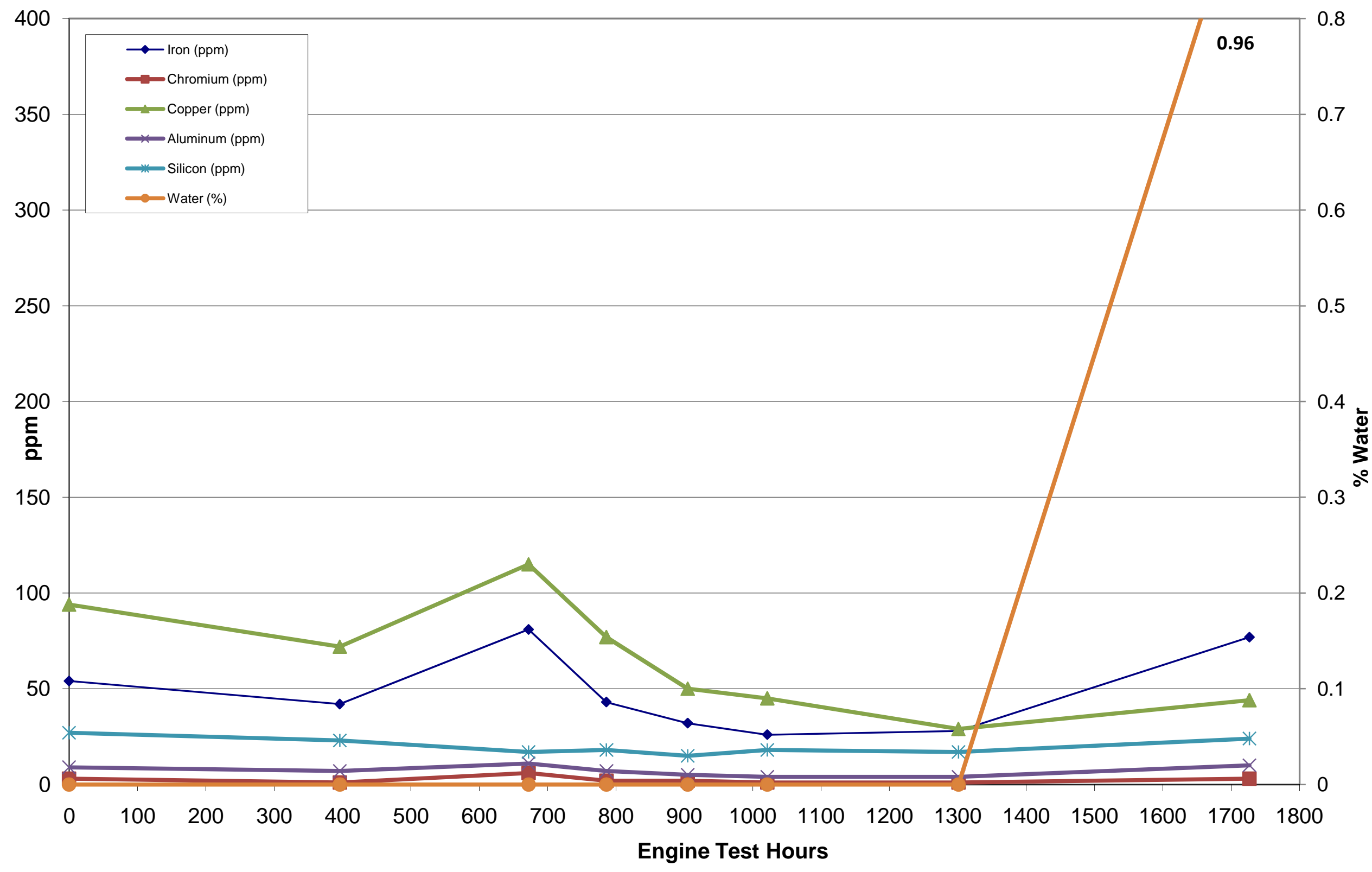


HICE Durability Vehicle: 5564

\section{Staveley Services Oil Analysis Results: TAN \& TBN}

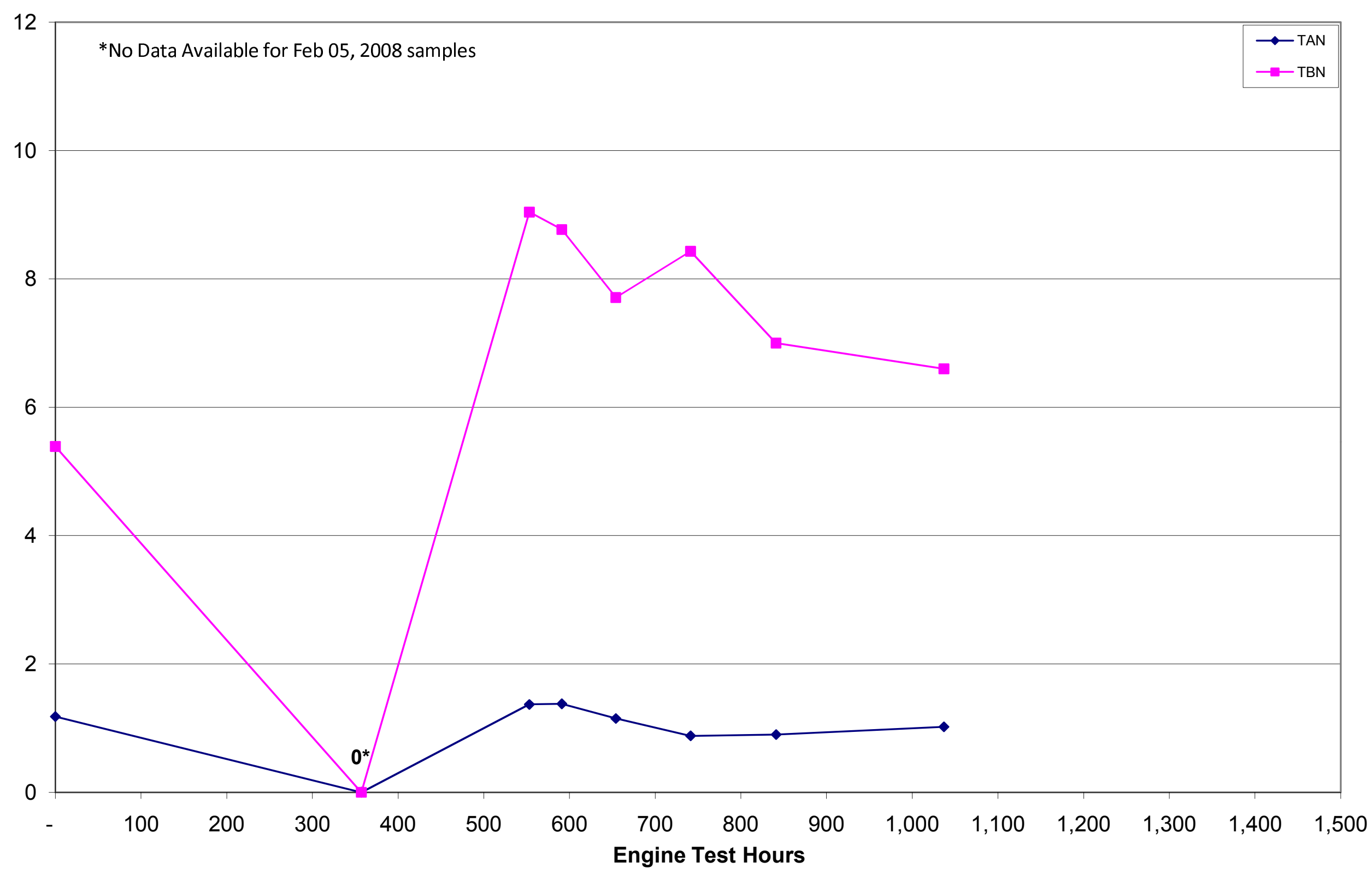


HICE Durability Vehicle: 5564

BTS Oil Analysis Results: TAN \& TBN

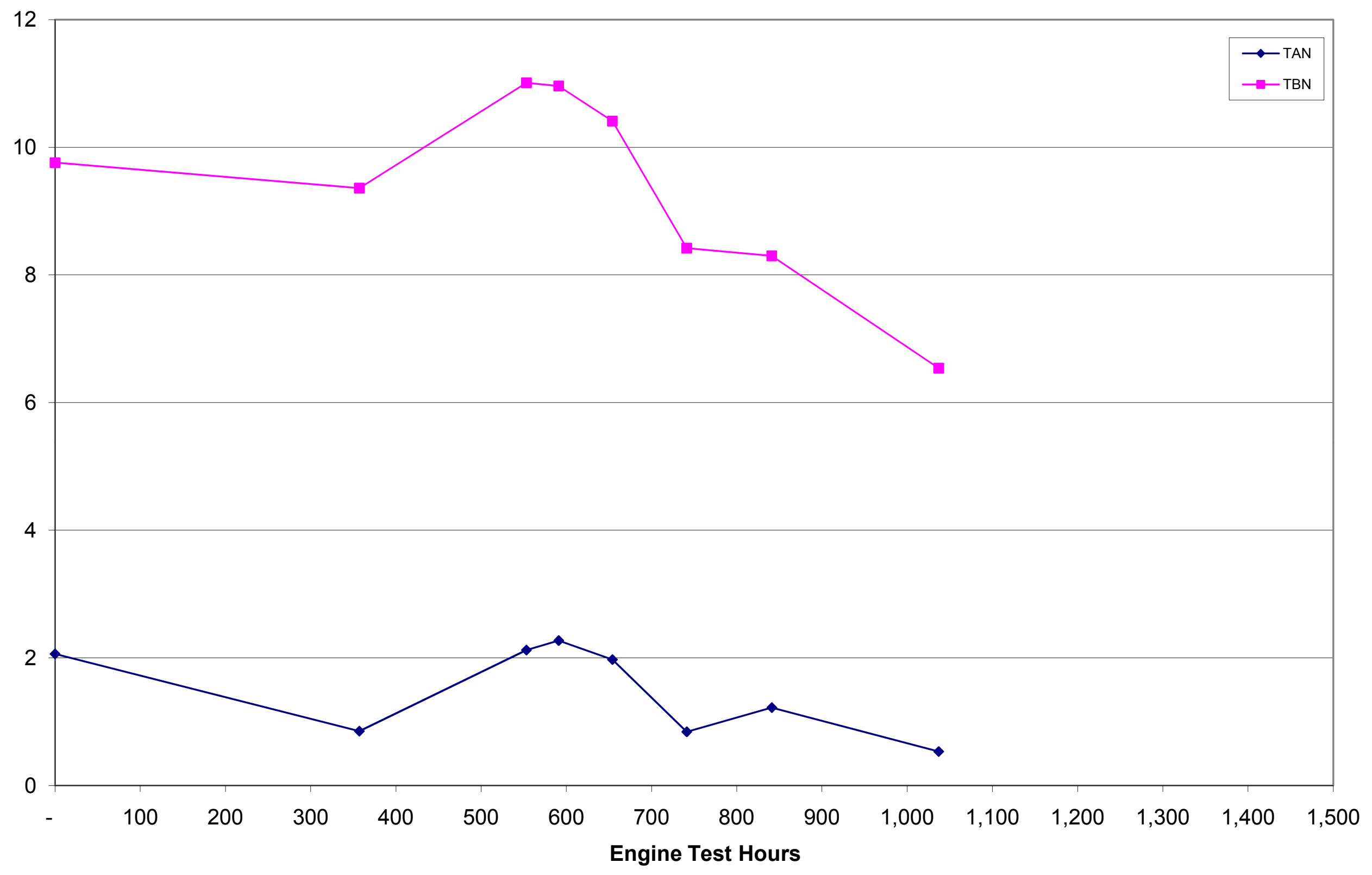


HICE Durability Vehicle: 5564

BTS Oil Analysis Results--Wear Metals

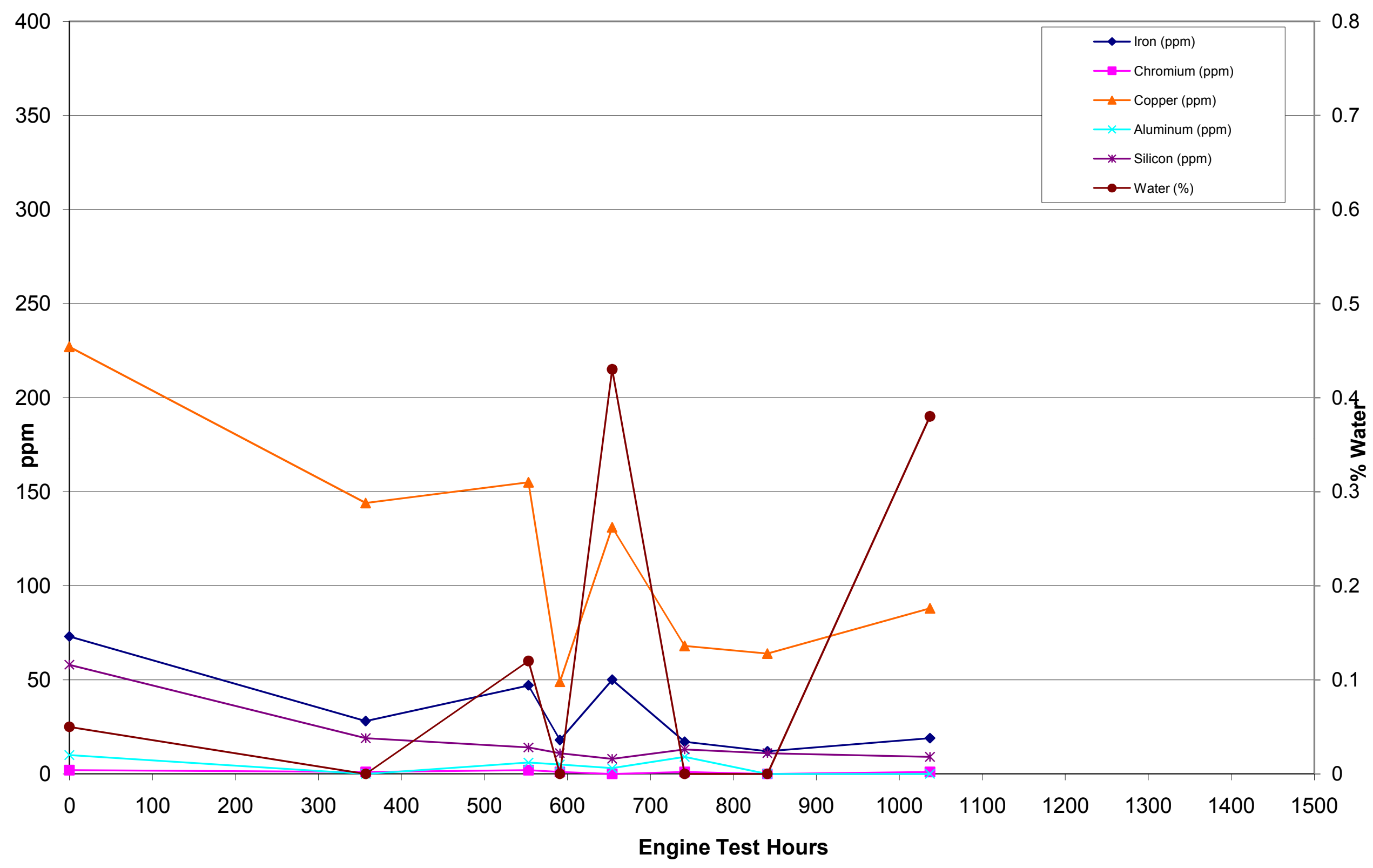


HICE Durability Vehicle: 5564

Staveley Services Oil Analysis Results--Wear Metals

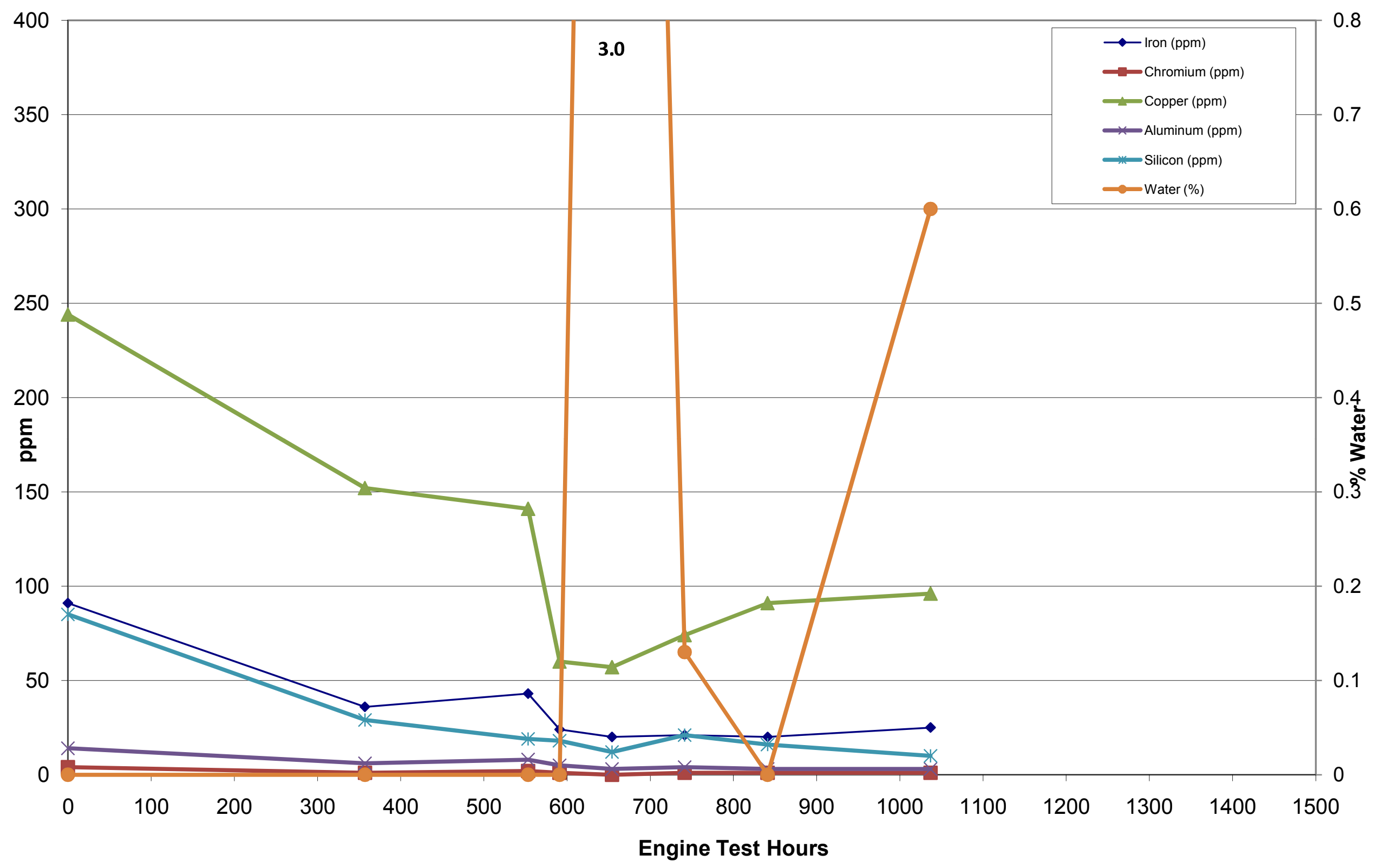


HICE Durability Vehicle: 5565

\section{Staveley Services Oil Analysis Results: TAN \& TBN}

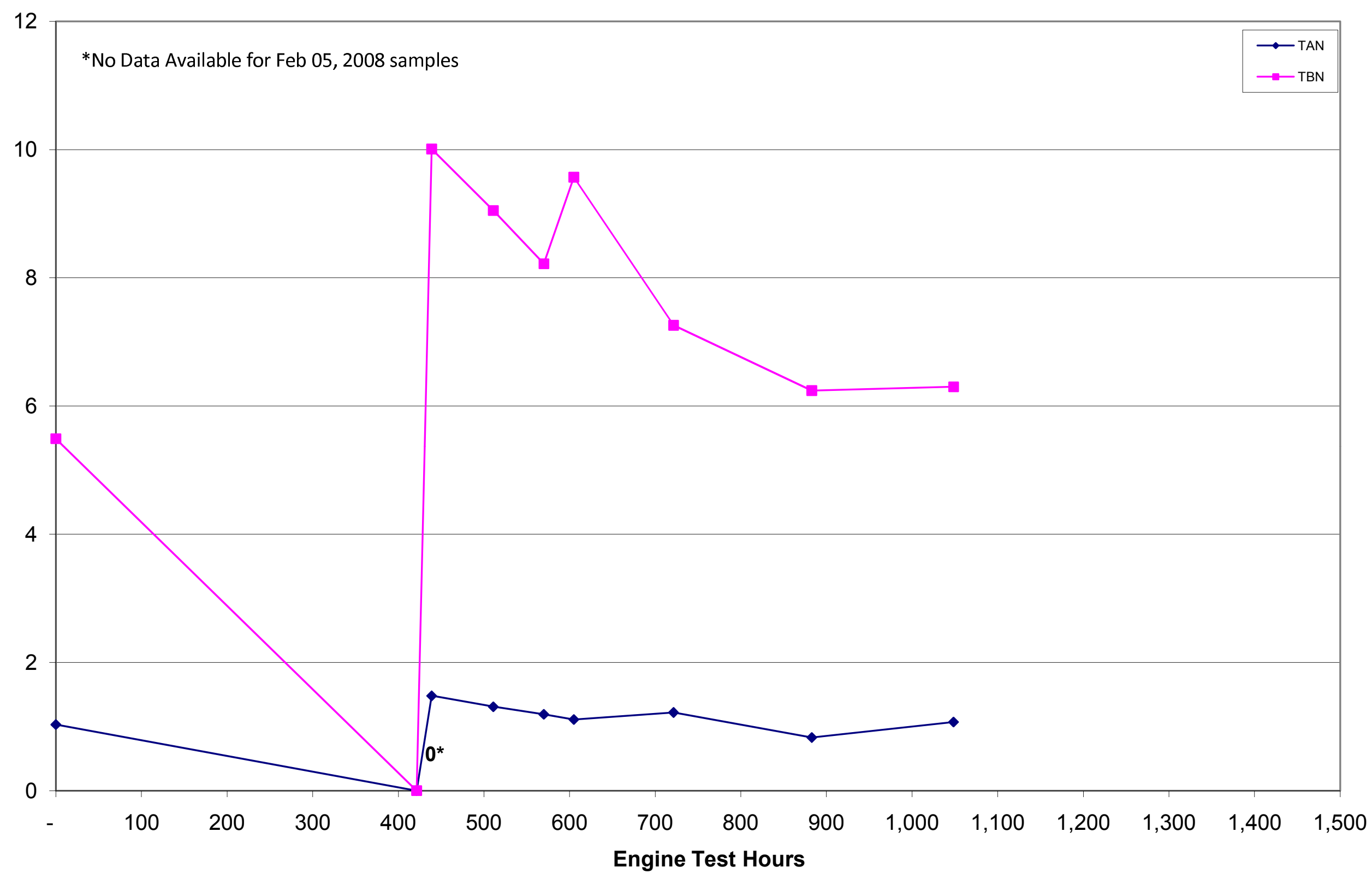


HICE Durability Vehicle: 5565

BTS Oil Analysis Results: TAN \& TBN

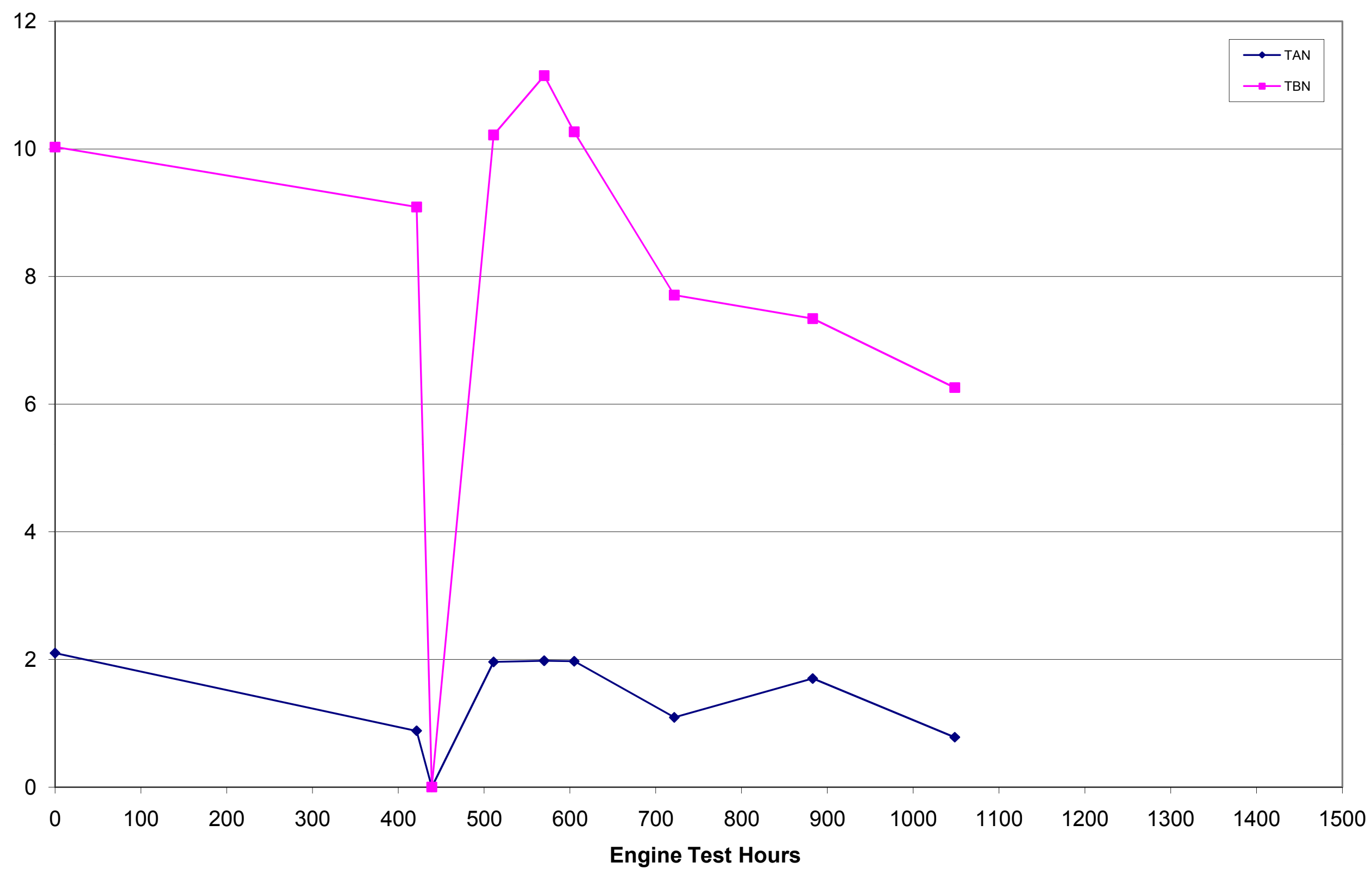


HICE Durability Vehicle: 5565

BTS Oil Analysis Results--Wear Metals

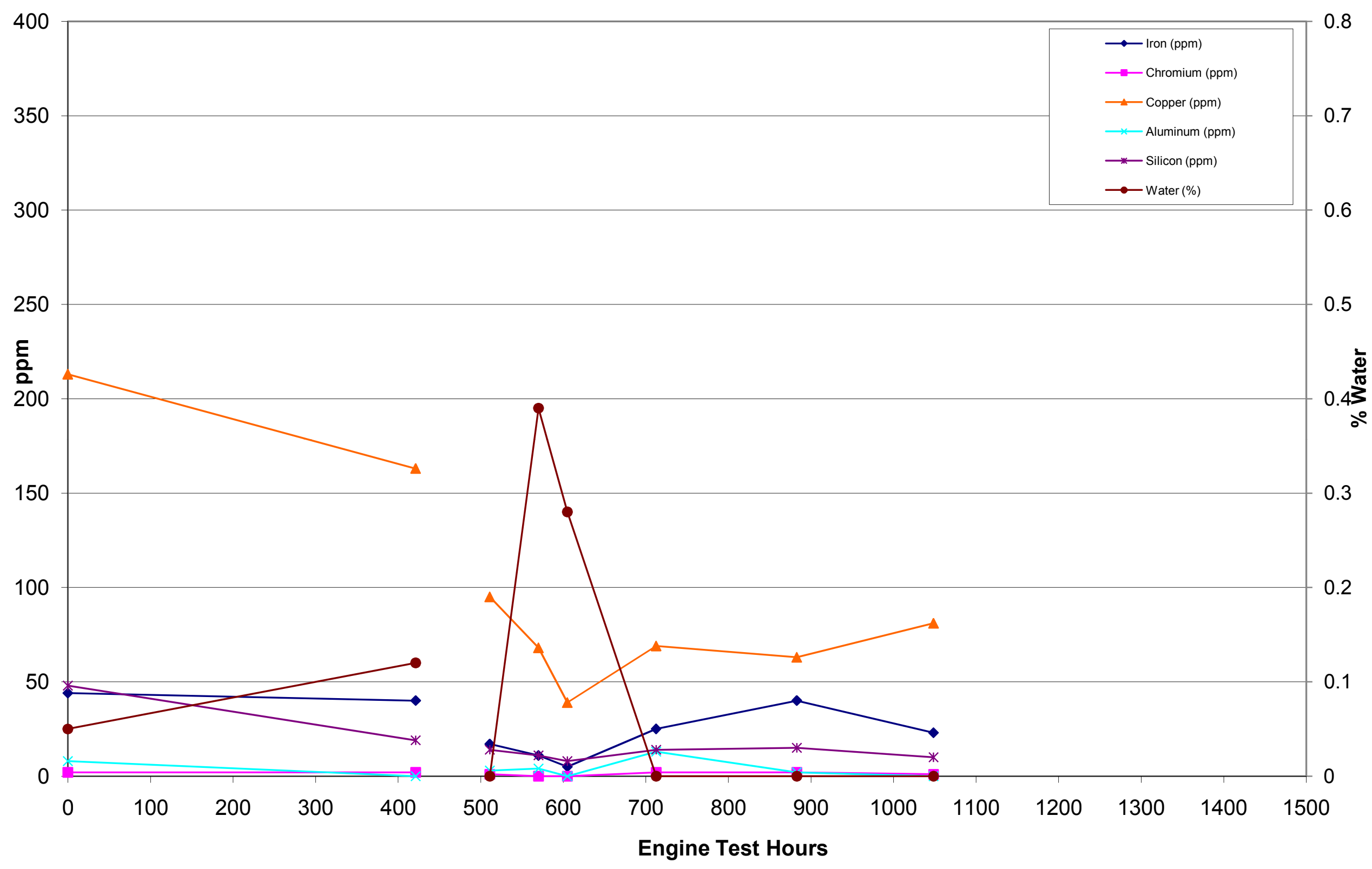


HICE Durability Vehicle: 5565

Staveley Services Oil Analysis Results--Wear Metals

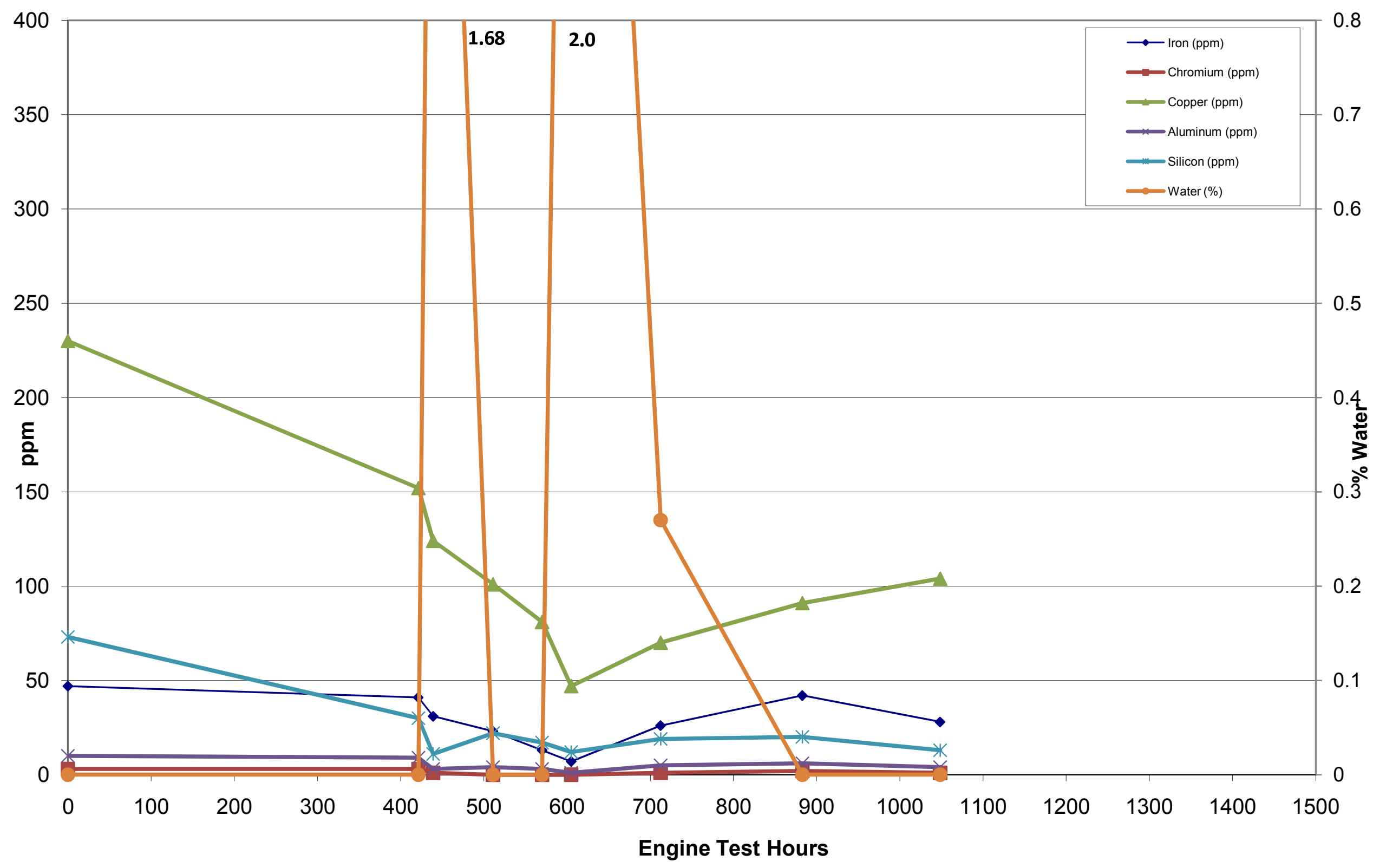


HICE DurabilityVehicle: 5566

Staveley Services Oil Analysis Results: TAN \& TBN

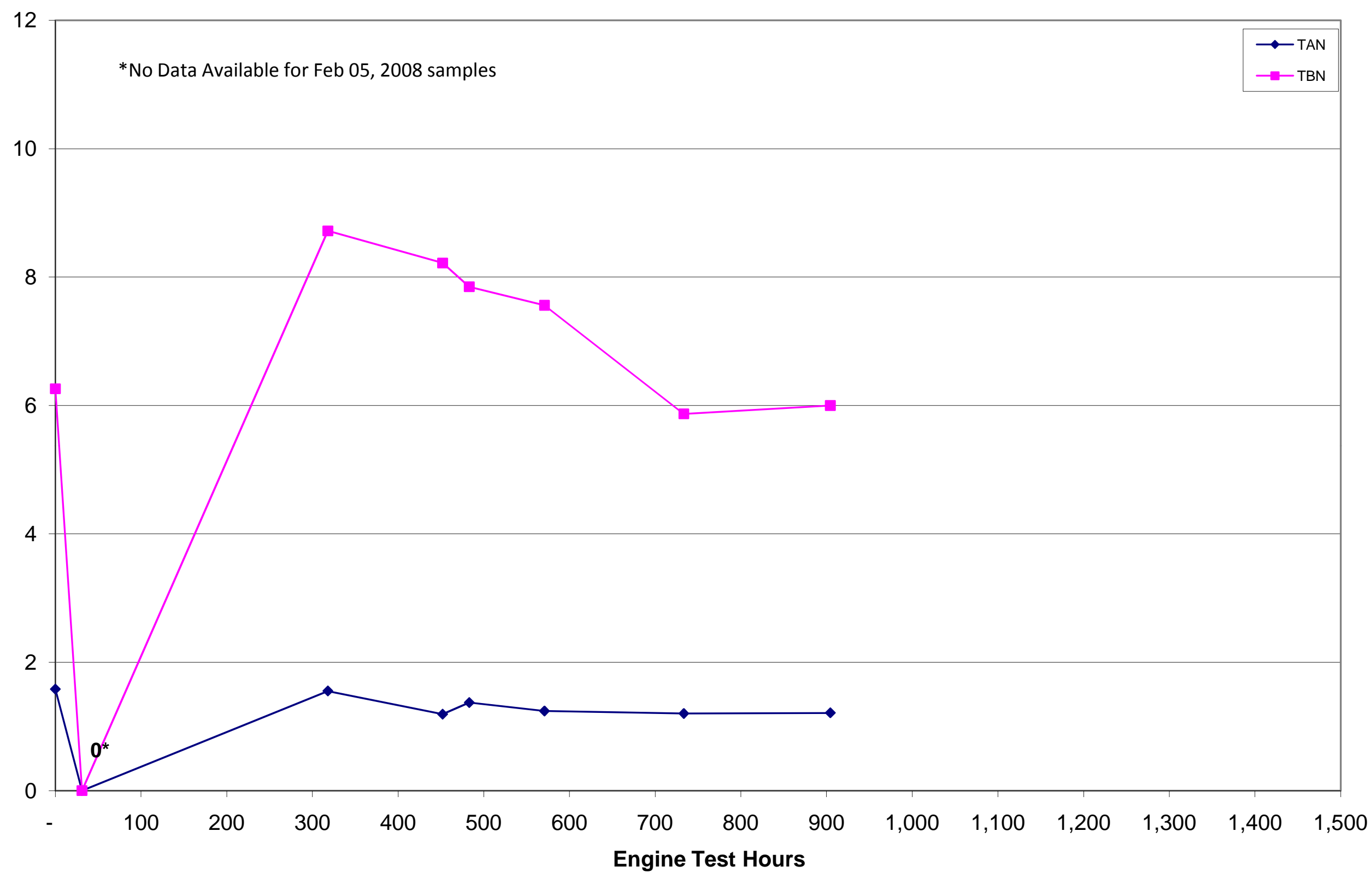


HICE Durability Vehicle: 5566

BTS Oil Analysis Results: TAN \& TBN

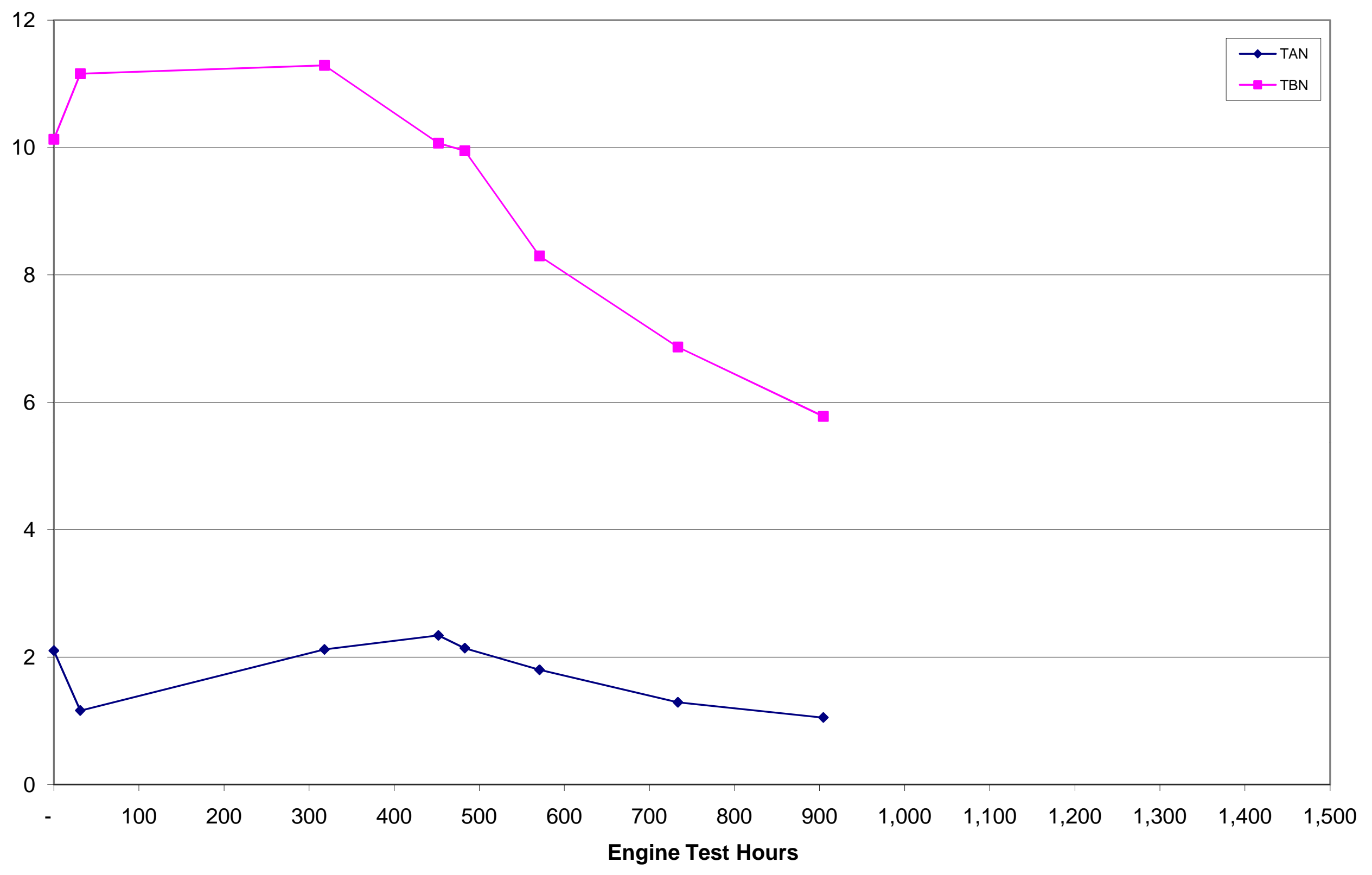


HICE Durability Vehicle: 5566

BTS Oil Analysis Results--Wear Metals

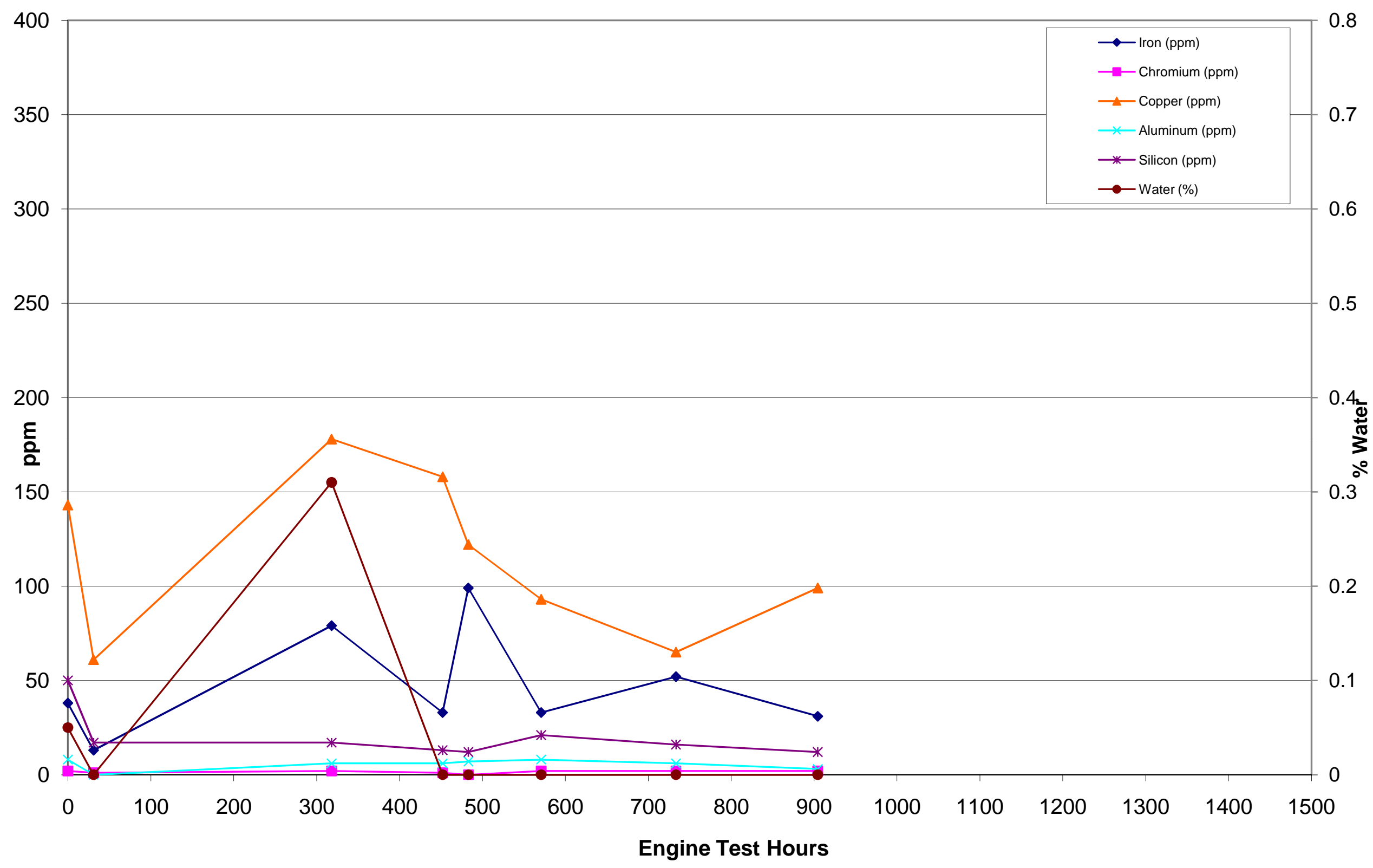


HICE Durability Vehicle: 5566

Staveley Services Oil Analysis Results--Wear Metals

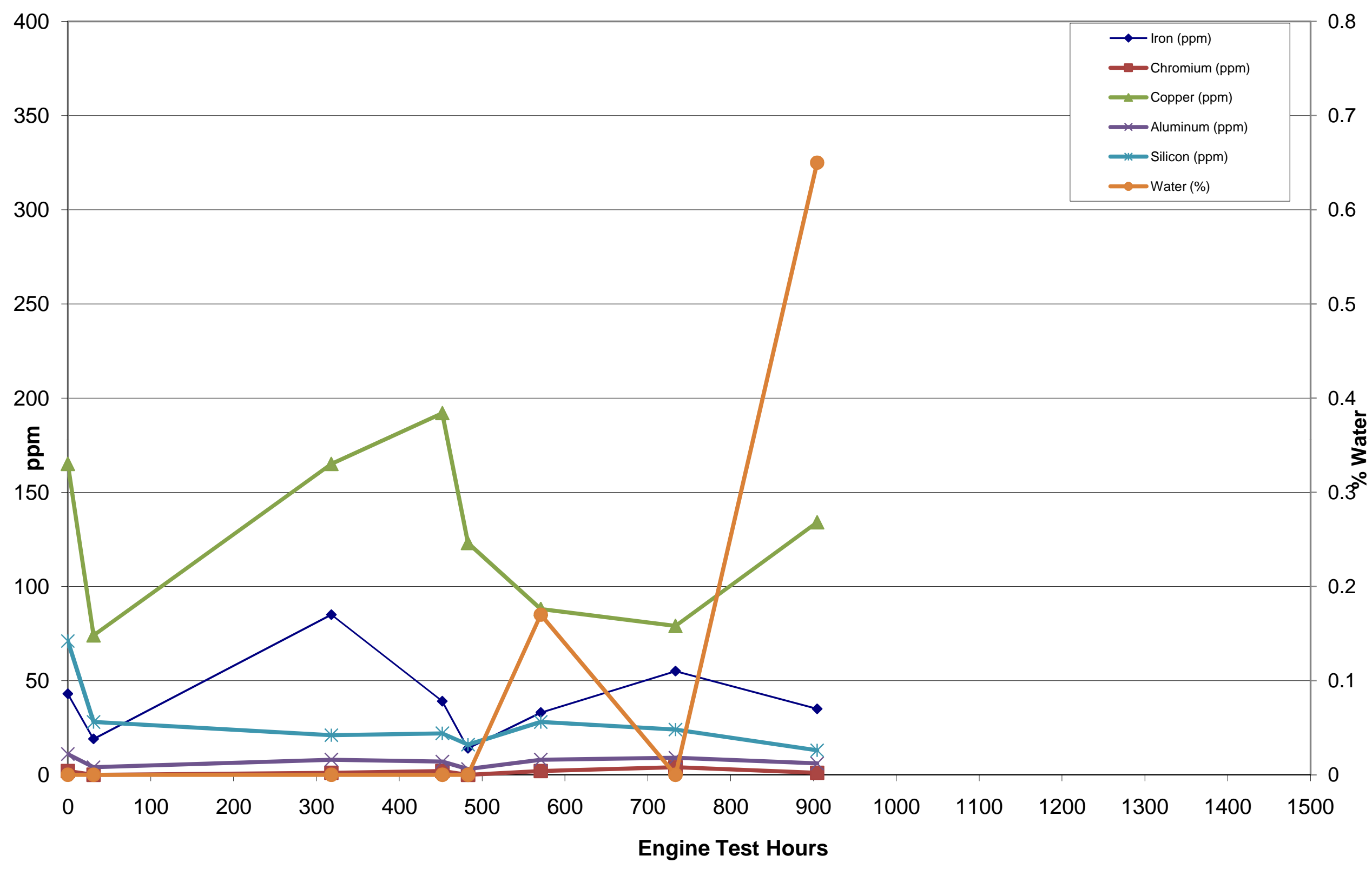


HICE Durability Vehicle: 5567

Staveley Services Oil Analysis Results: TAN \& TBN

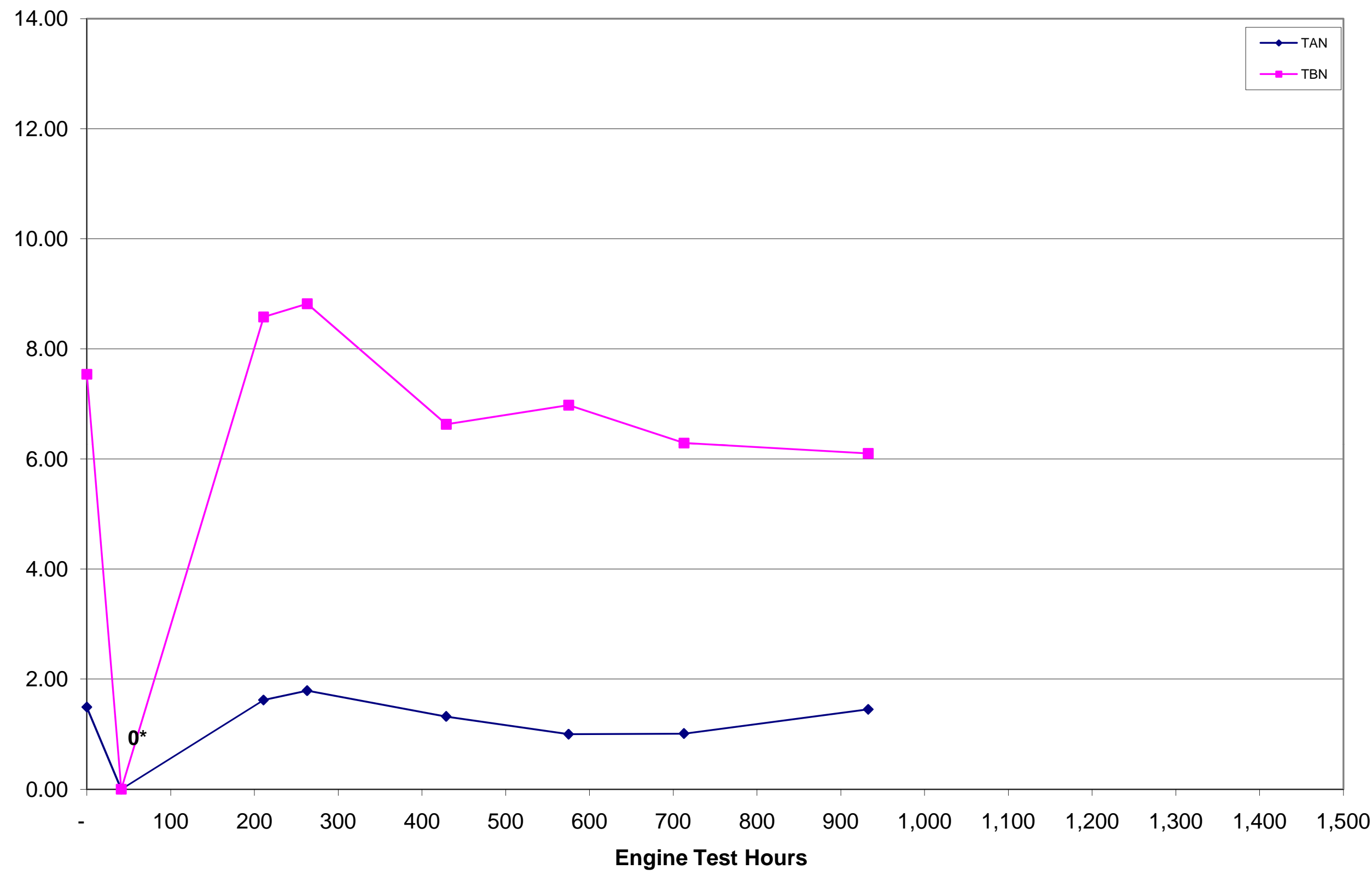


HICE Durability Vehicle: 5567

BTS Oil Analysis Results: TAN \& TBN

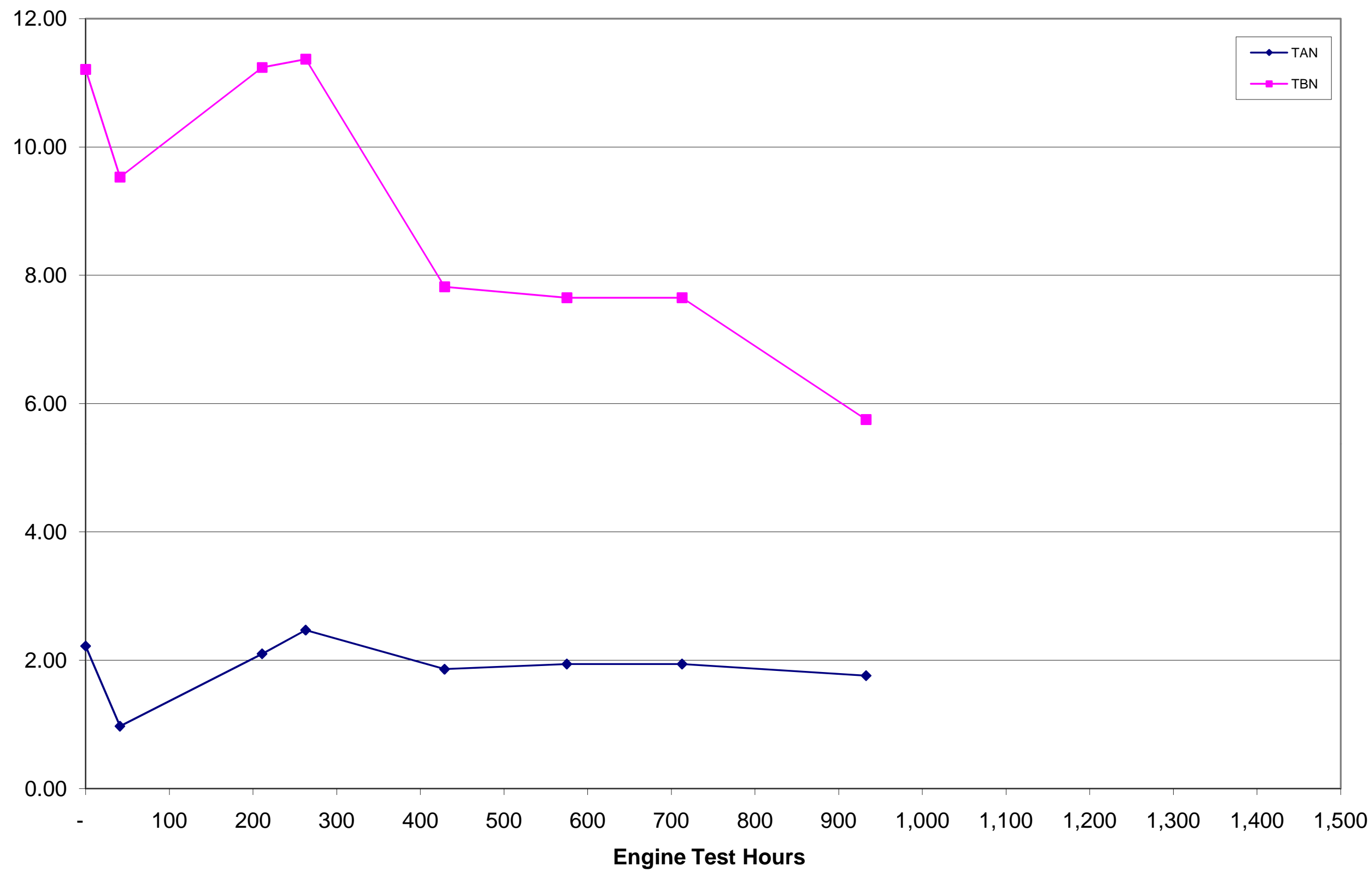


HICE Durability Vehicle: 5567

BTS Oil Analysis Results--Wear Metals

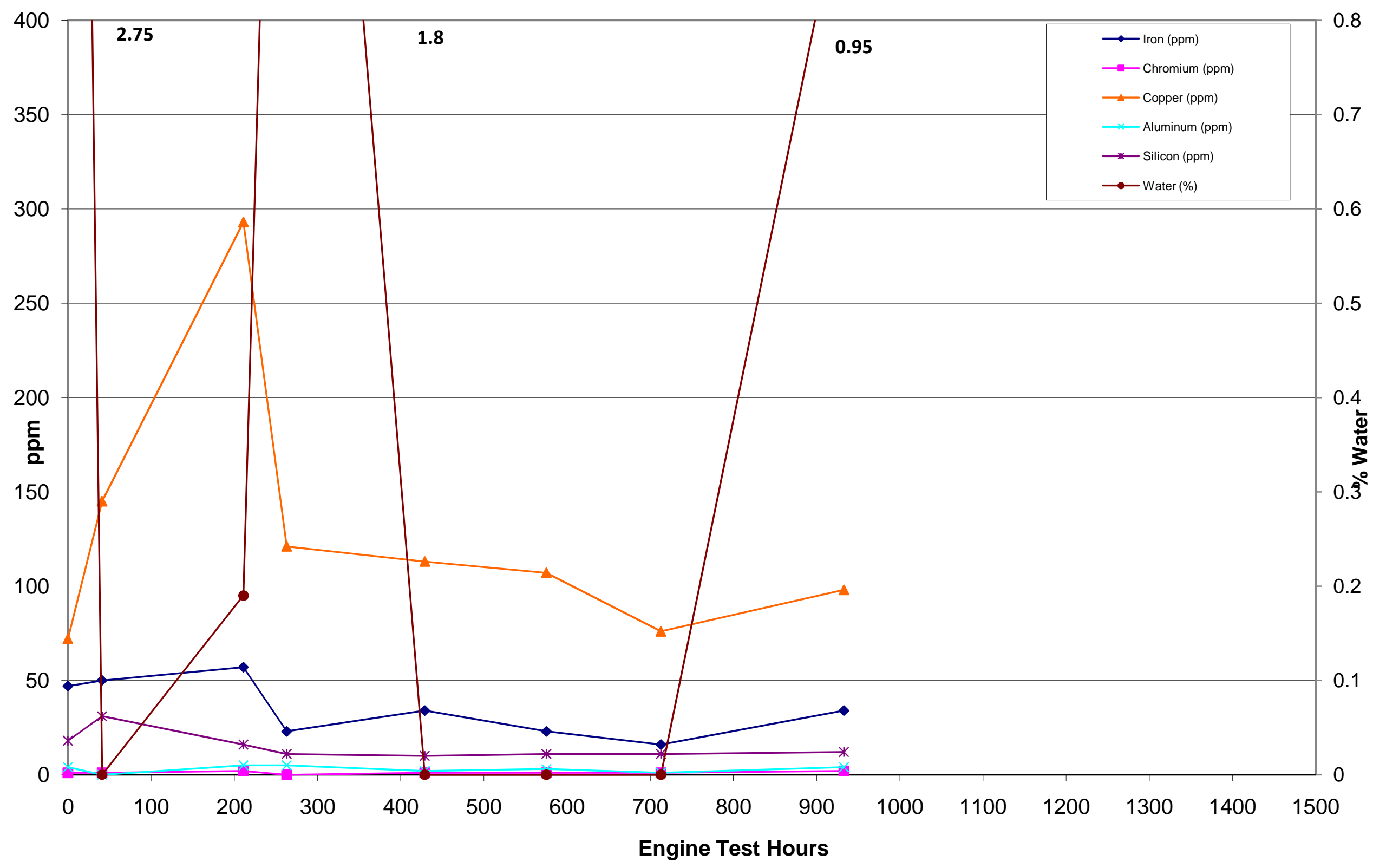


HICE Durability Vehicle: 5567

Staveley Services Oil Analysis Results--Wear Metals

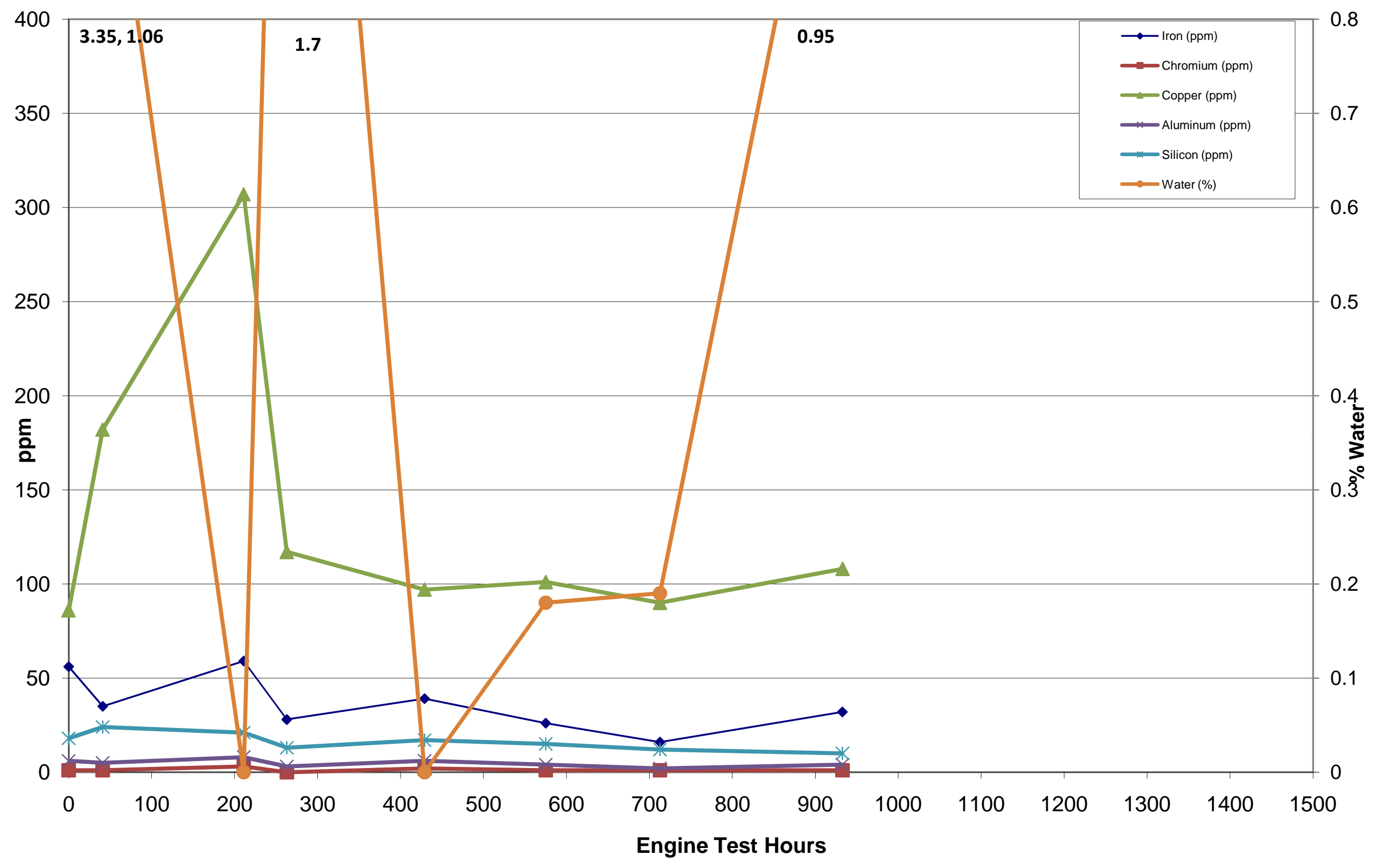


HICE Durability Vehicle: 6000

Staveley Services Oil Analysis Results: TAN \& TBN

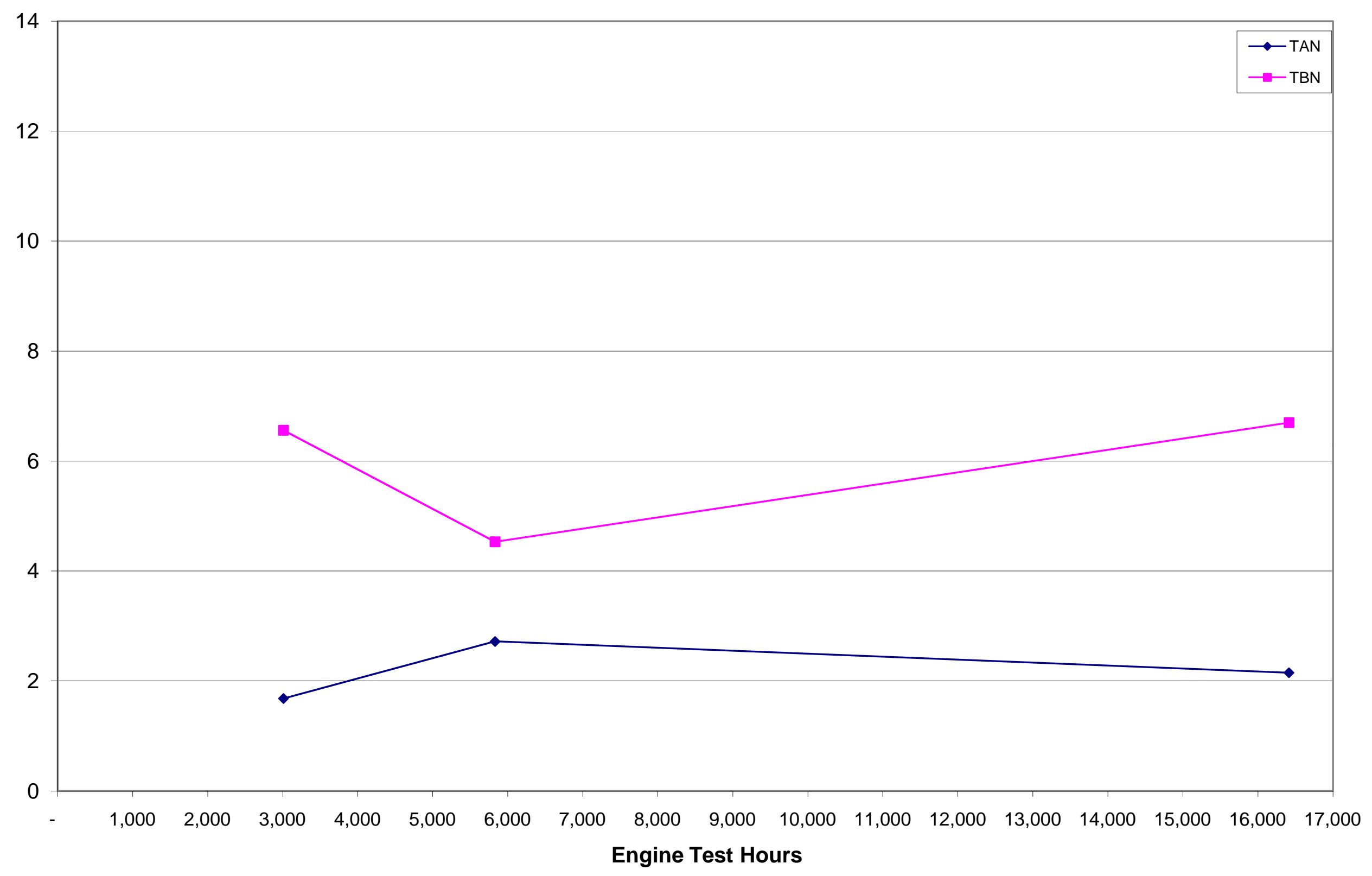


HICE Durability Vehicle: 6000

BTS Oil Analysis Results: TAN \& TBN

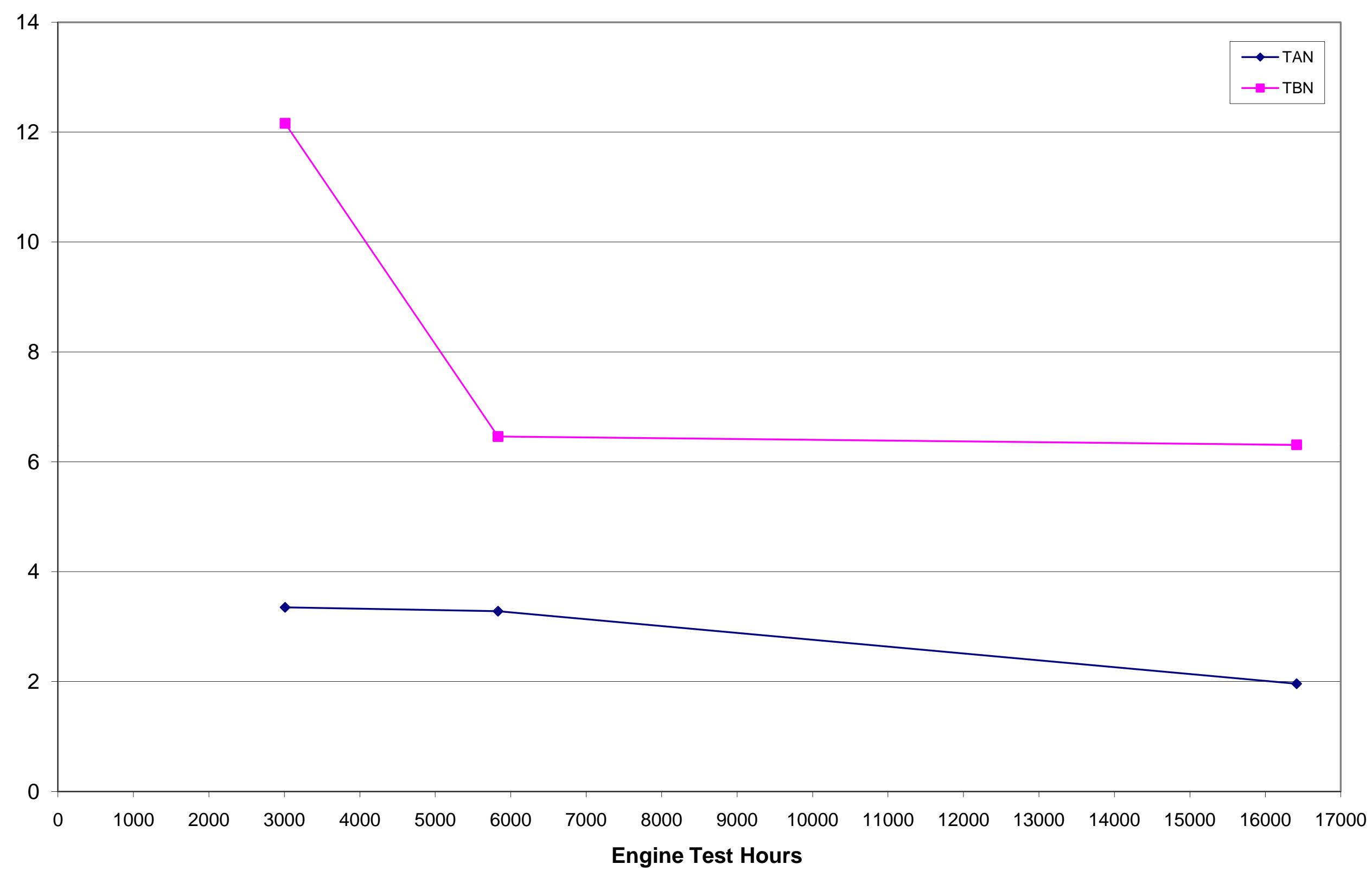


HICE Durability Vehicle: 6000

BTS Oil Analysis Results--Wear Metals

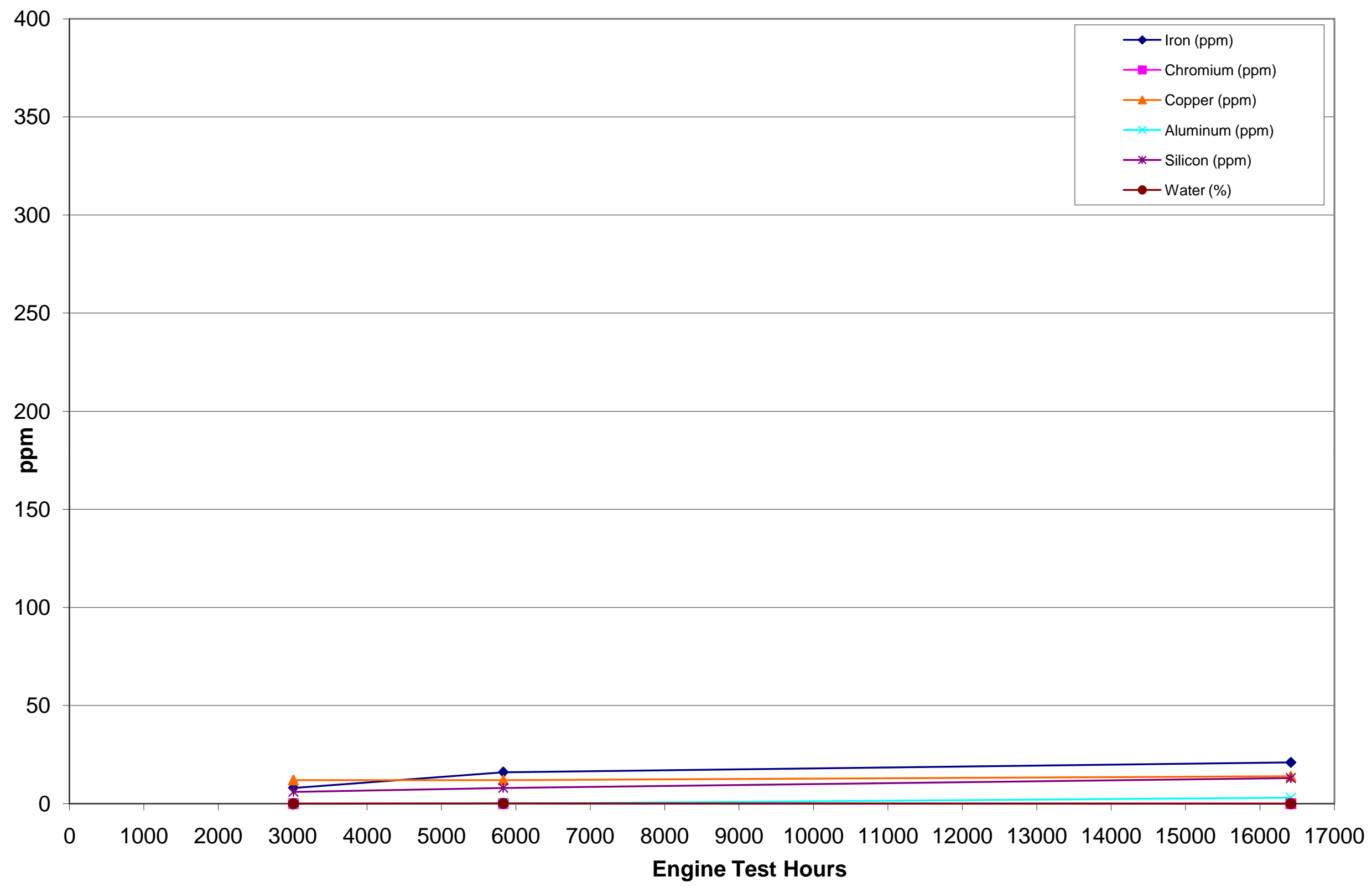


HICE Durability Vehicle: 6000

Staveley Services Oil Analysis Results--Wear Metals

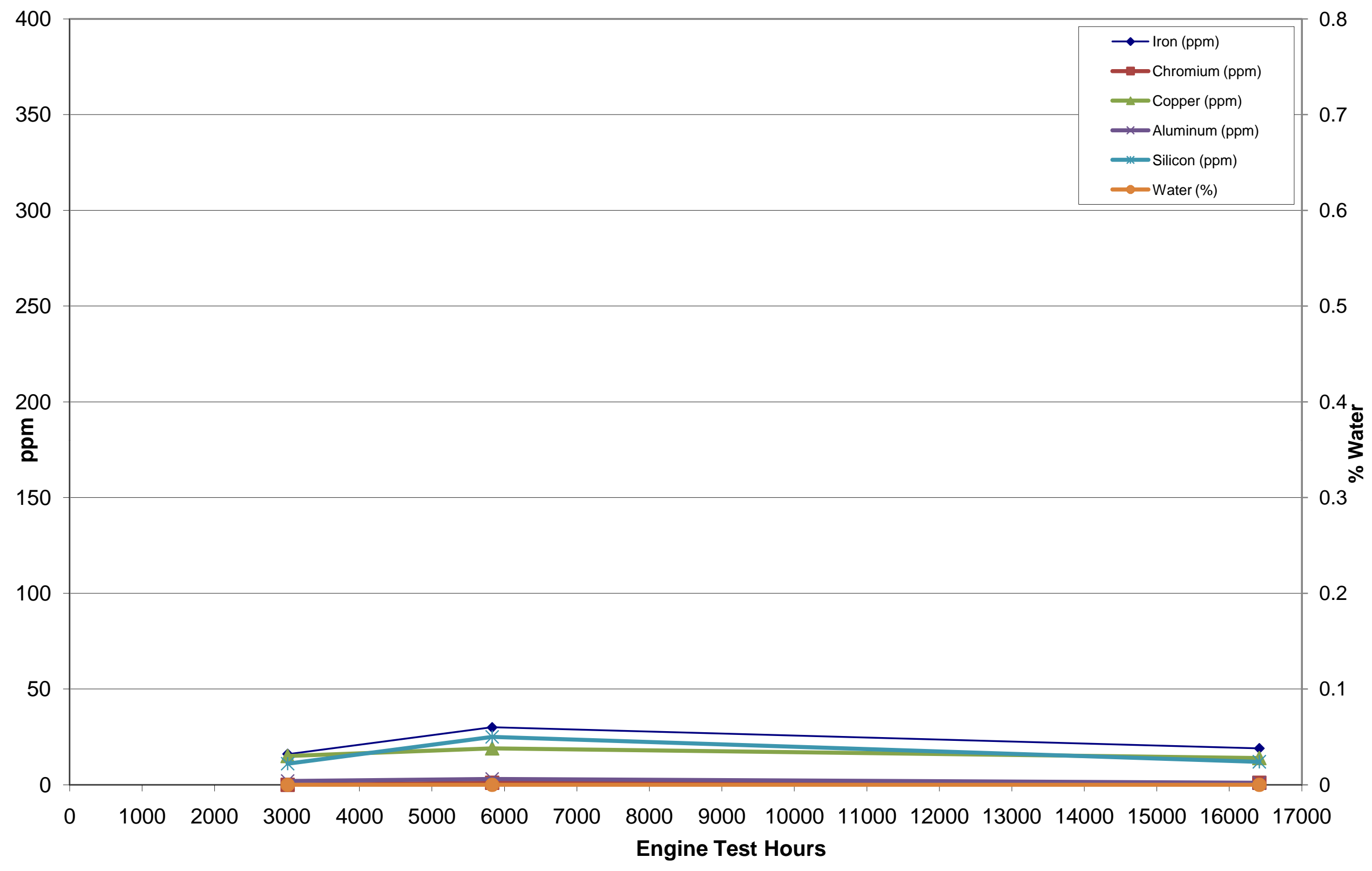


APPENDIX B

OIL ANALYSIS DATA 


\section{HICE SILVERADO PICKUP TRUCK 5000 EMISSIONS TEST RESULTS}

Vehicle: 2005 HICE Chevrolet Silverado, Vehicle Number 5000

\begin{tabular}{|c|c|c|c|c|c|c|c|c|c|c|c|c|c|c|c|c|c|c|c|c|}
\hline & \multicolumn{7}{|c|}{ 1st EPA75 } & \multicolumn{3}{|c|}{ 1st HYWFET } & \multicolumn{7}{|c|}{ 2nd EPA75 } & \multicolumn{3}{|c|}{ 2nd HYWFET } \\
\hline Date & \multicolumn{2}{|c|}{ Bag 1} & \multicolumn{2}{|c|}{ Bag 2} & \multicolumn{2}{|c|}{ Bag 3} & \multirow[t]{2}{*}{$\mathrm{FE}$} & \multicolumn{2}{|c|}{ Bag 1} & \multirow[t]{2}{*}{\begin{tabular}{|l|}
$\mathrm{FE}$ \\
\end{tabular}} & \multicolumn{2}{|c|}{ Bag 1} & \multicolumn{2}{|c|}{ Bag 2} & \multicolumn{2}{|c|}{ Bag 3} & I $\mathrm{FE}$ & \multicolumn{2}{|c|}{ Bag 1} & \multirow[t]{2}{*}{$\mathrm{FE}$} \\
\hline & NOx & $\mathrm{CO} 2$ & NOx & $\mathrm{CO} 2$ & NOx & $\mathrm{CO} 2$ & & NOx & $\mathrm{CO2}$ & & NOx & $\mathrm{CO} 2$ & NOx & $\mathrm{CO} 2$ & NOx & $\mathrm{CO} 2$ & & NOx & $\mathrm{CO} 2$ & \\
\hline $2 / 28 / 2007$ & 0.0896 & 1.67 & T0.0385 & 0.08 & 0.0926 & 0.06 & 713.53 & 0.0330 & -0.16 & 21.03 & 0.0978 & -1.78 & 0.0361 & -1.01 & 0.0641 & -0.89 & $T 13.52$ & 0.0269 & 0.2 & 20.71 \\
\hline 9/27/2007 & 0.1024 & -1.07 & 0.0503 & -0.23 & 0.0020 & -0.01 & 14.12 & 0.0273 & -0.46 & 21.03 & 0.0891 & 3.43 & 0.0487 & 1.52 & 0.0876 & 3.57 & 13.7 & 0.0269 & 1.43 & 21.26 \\
\hline $3 / 18 / 2008$ & 0.0967 & 1.93 & 0.0508 & 1.58 & 0.0834 & 1.70 & 13.48 & 0.0226 & 0.63 & 20.29 & .0798 & 0.53 & 0.0 & 2.53 & 0.0783 & 1.82 & 13.43 & 0.0224 & 2.15 & 20.23 \\
\hline $8 / 22 / 2008$ & 0.0983 & 1.24 & 0.0556 & -0.38 & 0.0964 & 3.54 & 13.28 & 0.0352 & 1. & 20.45 & 0.0837 & 2.38 & & 1.7 & 0.0 & 0.75 & 13.21 & 0.02 & -1.77 & 20.42 \\
\hline $6 / 3 / 2009$ & 0.102 & $\mathrm{~N} / \mathrm{A}$ & 0.0666 & $\mathrm{~N} / \mathrm{A}$ & 0.1055 & $\mathrm{~N} / \mathrm{A}$ & 13.67 & 0.0196 & $\mathrm{~N} / \mathrm{A}$ & 20.79 & 0.1118 & $\mathrm{~N} / \mathrm{A}$ & 0.06 & $\mathrm{~N} / \mathrm{A}$ & 0.1103 & $\mathrm{~N} / \mathrm{A}$ & 13.69 & 0.0244 & $\mathrm{~N} / \mathrm{A}$ & 20.76 \\
\hline & & & I & & I & & I & & & & & & & & I & & I & & & \\
\hline
\end{tabular}

All units are $\mathrm{g} / \mathrm{mi}$ except Fuel Economy (FE) which is mi/kg

All data measured and recorded at Argonne National Laboratory, Advanced Powertrain Research Facility 


\section{IWHUP HICE PICKUP TRUCK 5567 EMISSIONS TEST RESULTS}

Vehicle: 2006 HICE GMC Sierra, Vehicle Number 5567

\begin{tabular}{|c|c|c|c|c|c|c|c|c|c|c|c|c|c|c|c|c|c|c|c|}
\hline \multirow{3}{*}{ Date } & \multicolumn{6}{|c|}{ 1st EPA75 } & \multicolumn{3}{|c|}{ 1st HYWFET } & \multicolumn{7}{|c|}{ 2nd EPA75 } & \multicolumn{3}{|c|}{ 2nd HYWFET } \\
\hline & \multicolumn{2}{|c|}{ Bag 1} & \multicolumn{2}{|c|}{ Bag 2} & Bag 3 & $\mathrm{FE}$ & \multicolumn{2}{|c|}{ Bag 1} & \multirow[t]{2}{*}{$\mathrm{FE}$} & \multicolumn{2}{|c|}{ Bag 1} & \multicolumn{2}{|c|}{ Bag 2} & \multicolumn{2}{|c|}{ Bag 3} & \multirow[t]{2}{*}{ FE } & \multicolumn{2}{|c|}{ Bag 1} & \multirow[t]{2}{*}{$\mathrm{FE}$} \\
\hline & NOx & $\mathrm{CO2}$ & NOx & $\mathrm{CO2}$ & NOx & $\mathrm{CO} 2 \mathrm{I}$ & NOx & $\mathrm{CO2}$ & & NOx & $\mathrm{CO} 2$ & NOx & $\mathrm{CO} 2$ & NOx & $\mathrm{CO2}$ & & NOx & $\mathrm{CO} 2$ & \\
\hline 2/28/2007 & 0.1084 & -3.37 & 0.0798 & 2.18 & 0.1091 & \begin{tabular}{l|l|l}
1.35 & 13.34 \\
\end{tabular} & 0.0488 & 0.63 & 19.59 & 0.1392 & 1.72 & 0.0810 & 0.78 & 0.1048 & 1.02 & T13.47 & 0.0501 & -0.3 & 19.69 \\
\hline $11 / 1 / 2007$ & 0.1186 & 2.660 & 0.0826 & -1.80 & 0.1186 & \begin{tabular}{l|l}
0.65 & 13.47 \\
\end{tabular} & 0.0458 & 1.18 & 20.14 & 0.1047 & 0.49 & 0.0762 & -0.45 & 0.1177 & 0.91 & 13.49 & $\mathrm{~N} / \mathrm{A}$ & $\mathrm{N} / \mathrm{A}$ & 19.31 \\
\hline $3 / 21 / 2008$ & 0.1187 & 1.38 & 0.0865 & -0.32 & 0.1329 & \begin{tabular}{|l|l|}
2.47 & 13.39 \\
\end{tabular} & 0.0673 & 1.31 & 19.97 & 0.1561 & 1.16 & 0.092 & 2.28 & 0.1379 & 0.79 & 13.29 & 0.0432 & 17 & 19.69 \\
\hline $8 / 19 / 2008$ & 0.1487 & -1.55 & 0.0907 & 0.69 & 0.1208 & $\begin{array}{l}-0.54 \\
\end{array}$ & & 0.5 & 20.02 & 352 & 3.64 & & 0.94 & 309 & -3.86 & 13.50 & 51 & -0.08 & 19.90 \\
\hline $6 / 5 / 2009$ & 0.1363 & $\mathrm{~N} / \mathrm{A}$ & 0.0907 & $\mathrm{~N} / \mathrm{A}$ & 0.1507 & $\begin{array}{llll}\mathrm{N} / \mathrm{A} & 13.26 \\
\end{array}$ & 0.03 & $\mathrm{~N} / \mathrm{A}$ & 19.3 & 0.1551 & $\mathrm{~N} / \mathrm{A}$ & & $\mathrm{N} / \mathrm{A}$ & 0.1525 & $\mathrm{~N} / \mathrm{A}$ & 13.28 & 0.0308 & $\mathrm{~N} / \mathrm{A}$ & 19.2 \\
\hline $4 / 20 / 2010$ & 0.1056 & $0.93 \mid$ & 0.0567 & -0.12 & 0.084 & 1.5812 .66 & 0.0352 & 1.27 & 18.53 & 0.1113 & -5.88 & 0.0421 & -7.63 & 0.0927 & -2.16 & 6 & 0.0341 & 1.29 & 18.02 \\
\hline
\end{tabular}

All units are $\mathrm{g} / \mathrm{mi}$ except Fuel Economy (FE) which is $\mathrm{mi} / \mathrm{kg}$

All data measured and recorded at Argonne National Laboratory, Advanced Powertrain Research Facility 


\section{IWHUP HICE PICKUP TRUCK 5563 EMISSIONS TEST RESULTS}

Vehicle: 2006 HICE GMC Sierra, Vehicle Number 5563

\begin{tabular}{|c|c|c|c|c|c|c|c|c|c|c|c|c|c|c|c|c|c|c|c|}
\hline & \multicolumn{6}{|c|}{ 1st EPA75 } & \multicolumn{3}{|c|}{ 1st HYWFET } & \multicolumn{7}{|c|}{ 2nd EPA75 } & \multicolumn{3}{|c|}{ 2nd HYWFET } \\
\hline \multirow[t]{2}{*}{ Date } & \multicolumn{2}{|c|}{ Bag 1} & \multicolumn{2}{|c|}{ Bag 2} & Bag 3 & FE & \multicolumn{2}{|c|}{ Bag 1} & \multirow[t]{2}{*}{ FE } & \multicolumn{2}{|c|}{ Bag 1} & \multicolumn{2}{|c|}{ Bag 2} & \multicolumn{2}{|c|}{ Bag 3} & I FE & \multicolumn{2}{|c|}{ Bag 1} & \multirow[t]{2}{*}{$\mathrm{FE}$} \\
\hline & NOx & $\mathrm{CO} 2$ & NOx & $\mathrm{CO} 2$ & NOx & $\mathrm{CO} 2 \mathrm{I}$ & NOx & $\mathrm{CO} 2$ & & NOx & $\mathrm{CO2}$ & NOx & $\mathrm{CO} 2$ & NOx & $\mathrm{CO} 2$ & & NOx & $\mathrm{CO} 2$ & \\
\hline $4 / 28 / 2010$ & 0.0752 & 5.24 & 0.0442 & 11.09 & 0.0862 & \begin{tabular}{|l|l|}
8.44 & 12.94 \\
\end{tabular} & 0.0248 & 3.84 & 19.18 & 0.0684 & 1.87 & 0.0334 & 4.62 & 0.0709 & 2.59 & $T 12.03$ & 0.0212 & 2.7 & 16.95 \\
\hline & & & 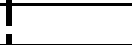 & & 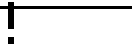 & 1 & & & & & & & & & & & & & \\
\hline & & & 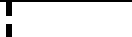 & & 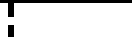 & 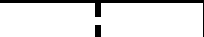 & & & & & & 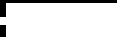 & & 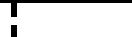 & & 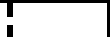 & & & \\
\hline & & & 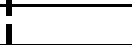 & & 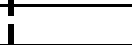 & 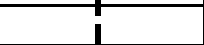 & & & & & ( & 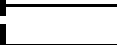 & & 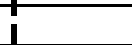 & & 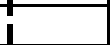 & & & \\
\hline & & & I & & $\mathrm{I}$ & I & & & & & 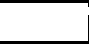 & I & & I & & I & & & \\
\hline & & & I & & I & I & & & & & & 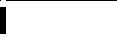 & & I & & i & & & \\
\hline
\end{tabular}

All units are $\mathrm{g} / \mathrm{mi}$ except Fuel Economy (FE) which is mi/kg

All data measured and recorded at Argonne National Laboratory, Advanced Powertrain Research Facility 


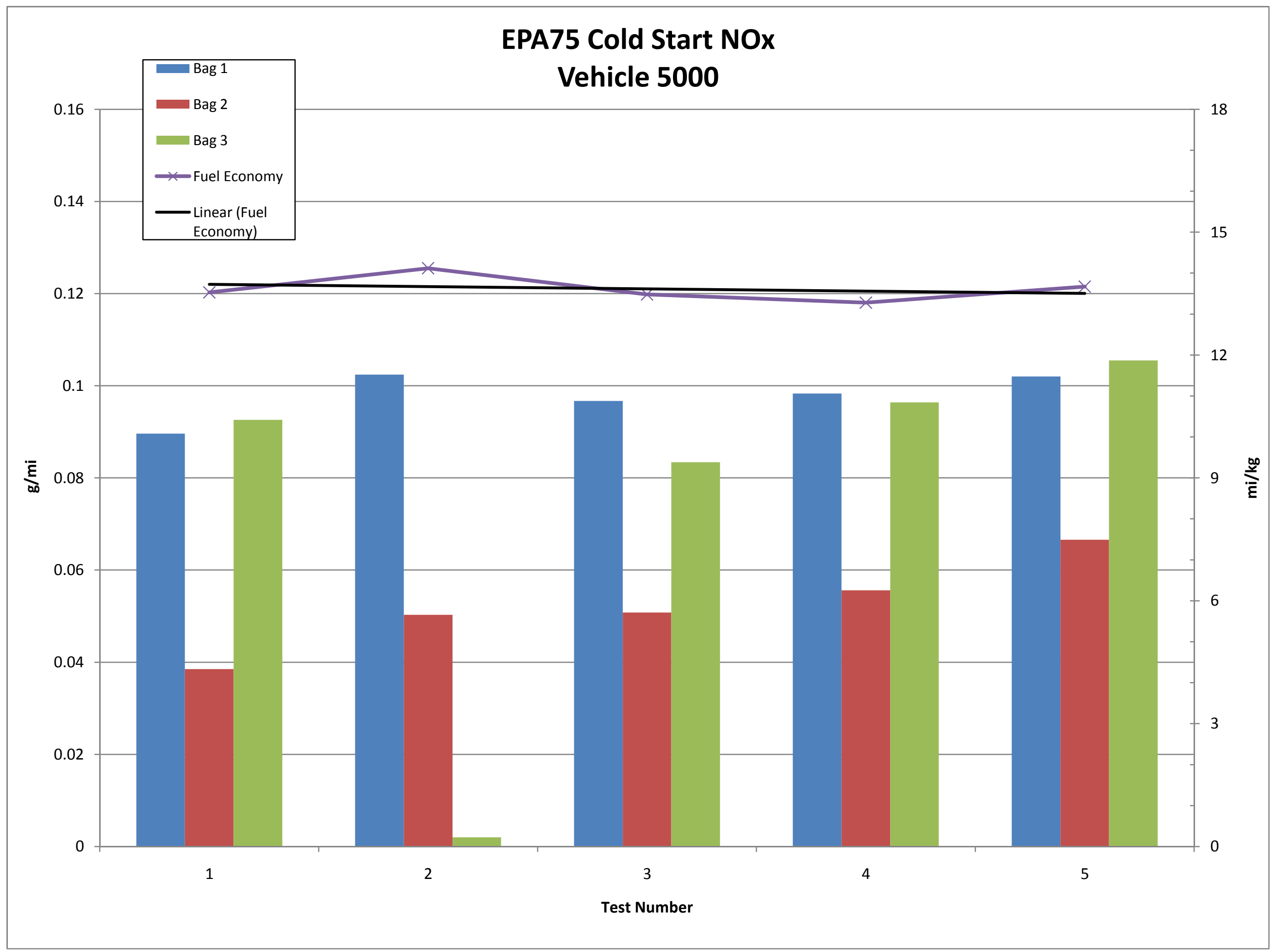




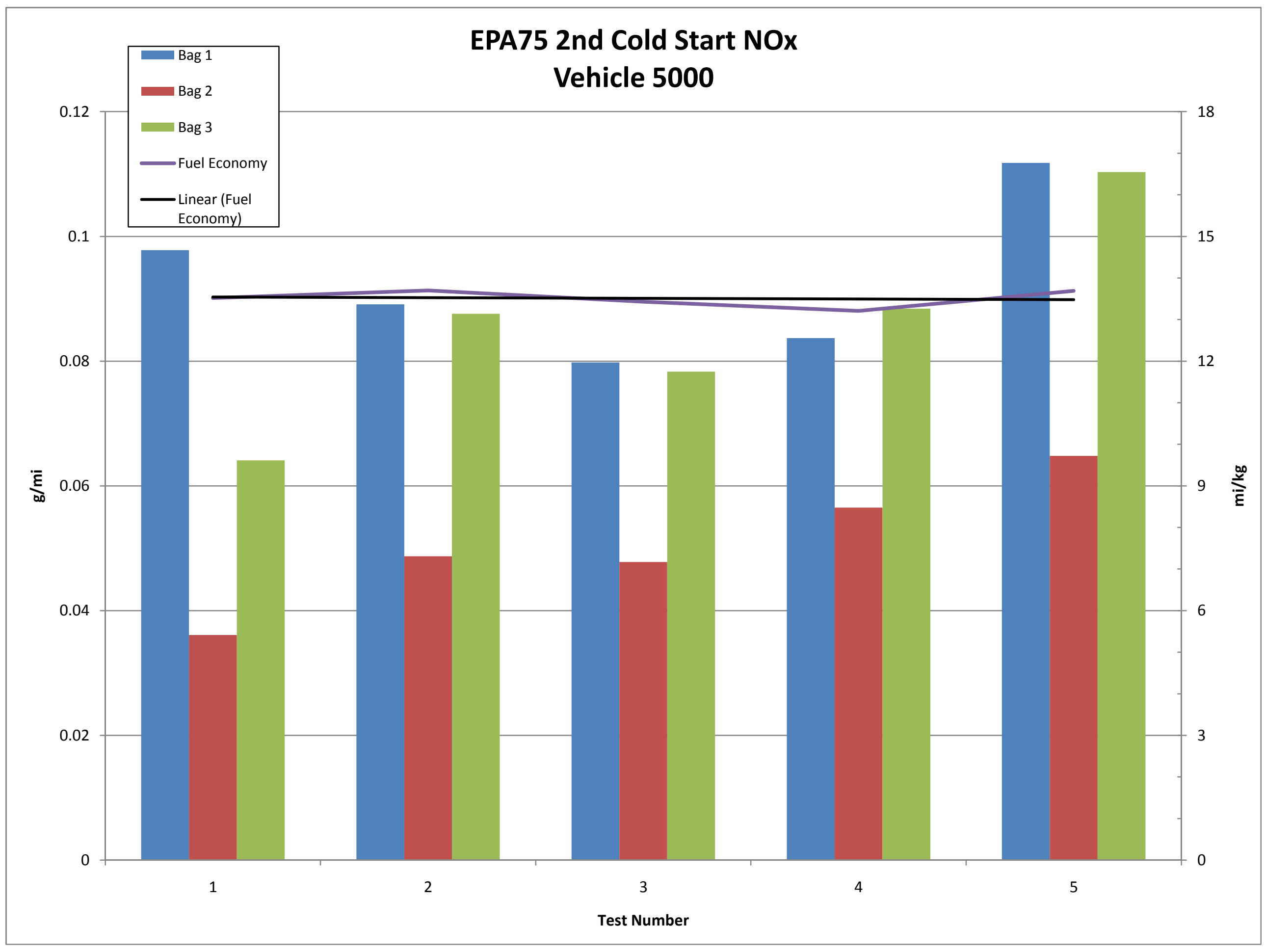




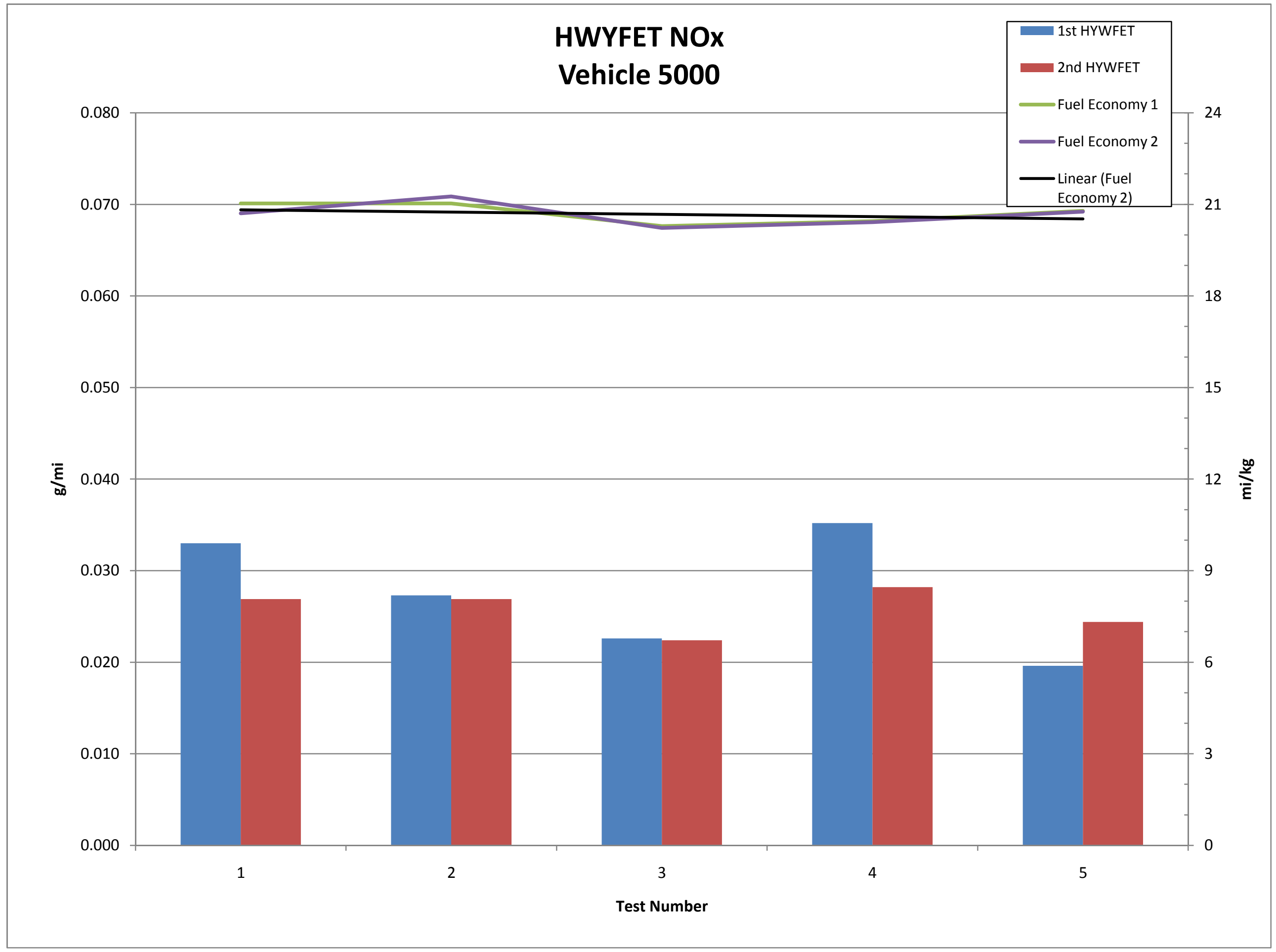




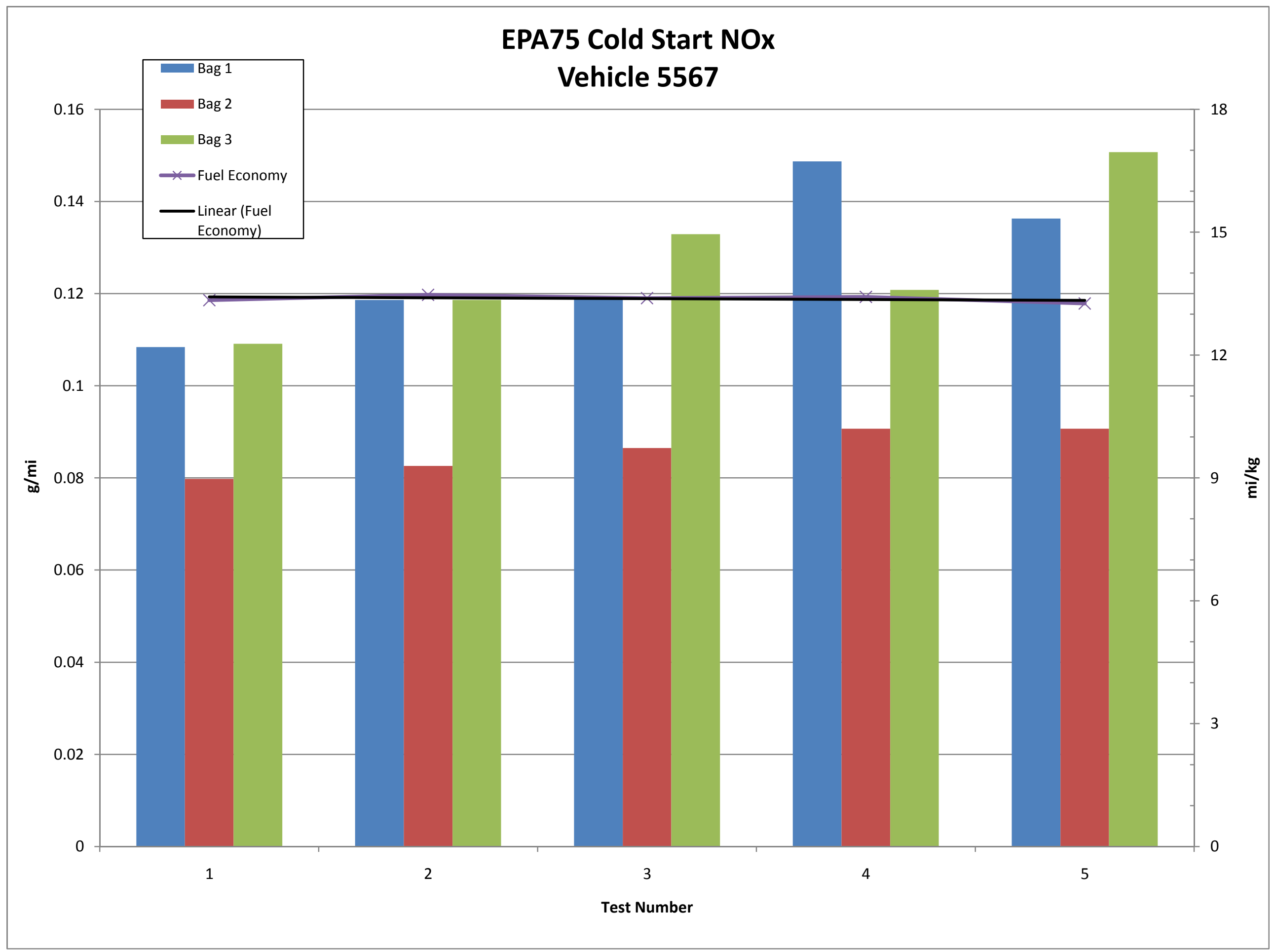




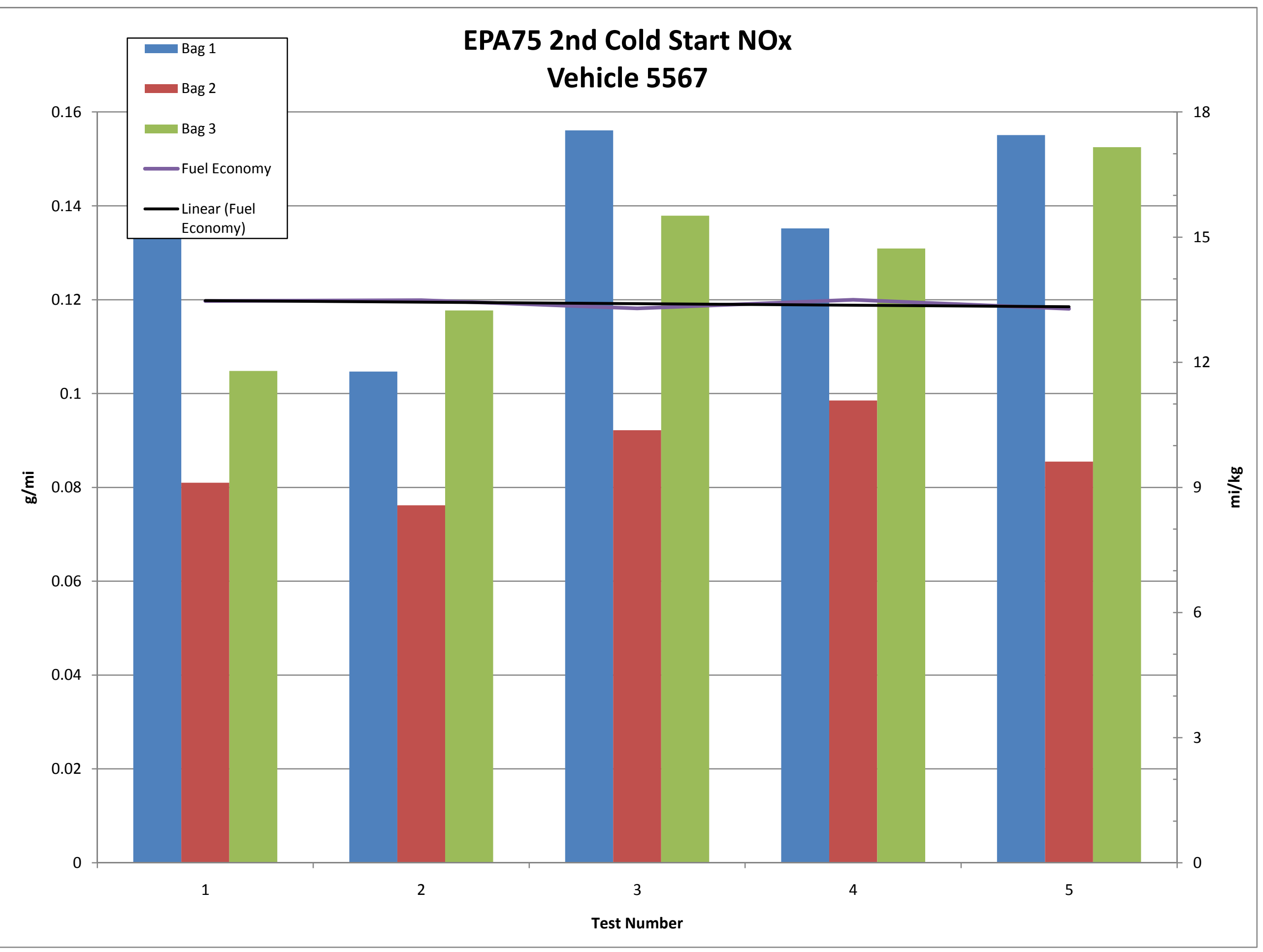




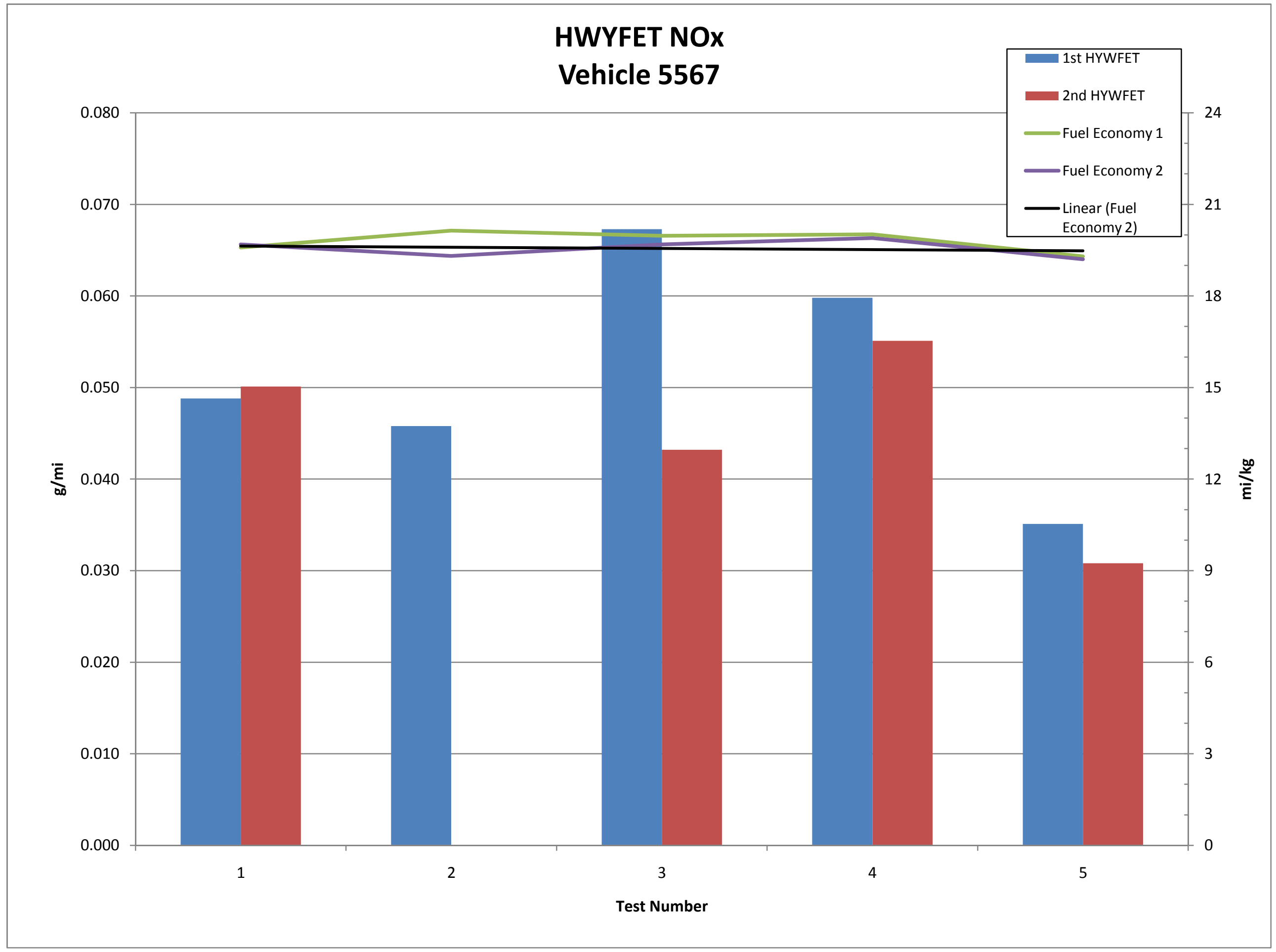




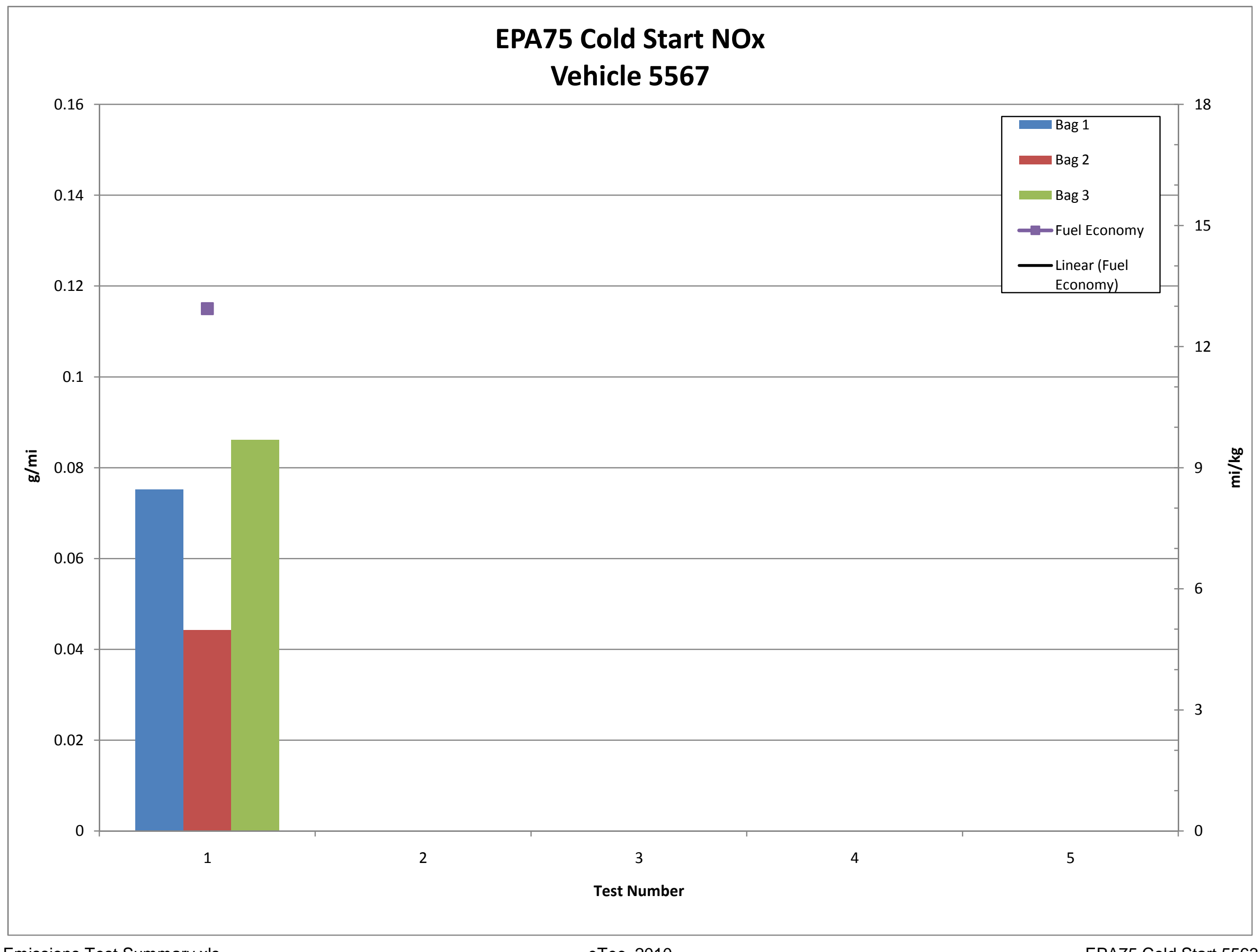




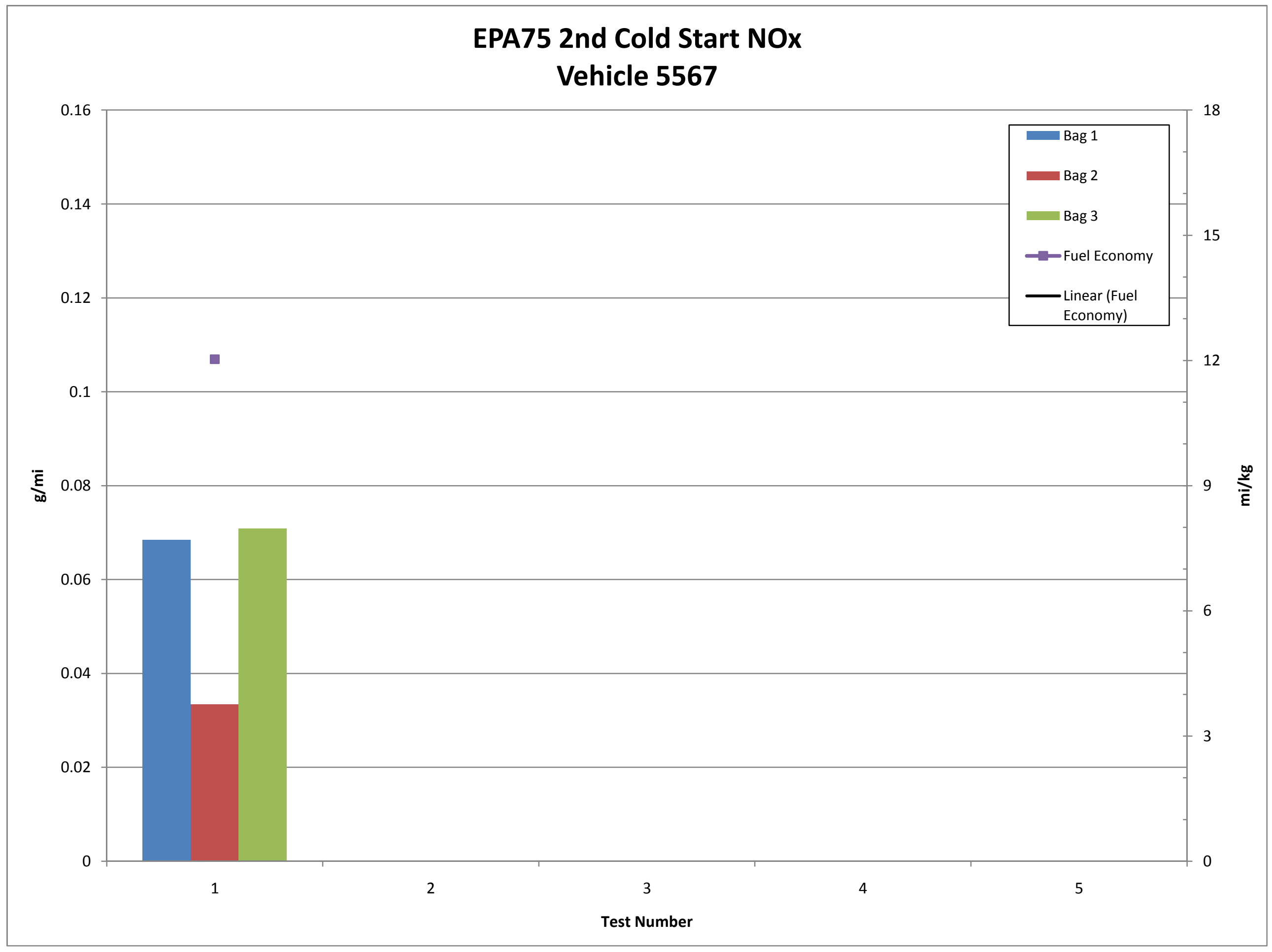




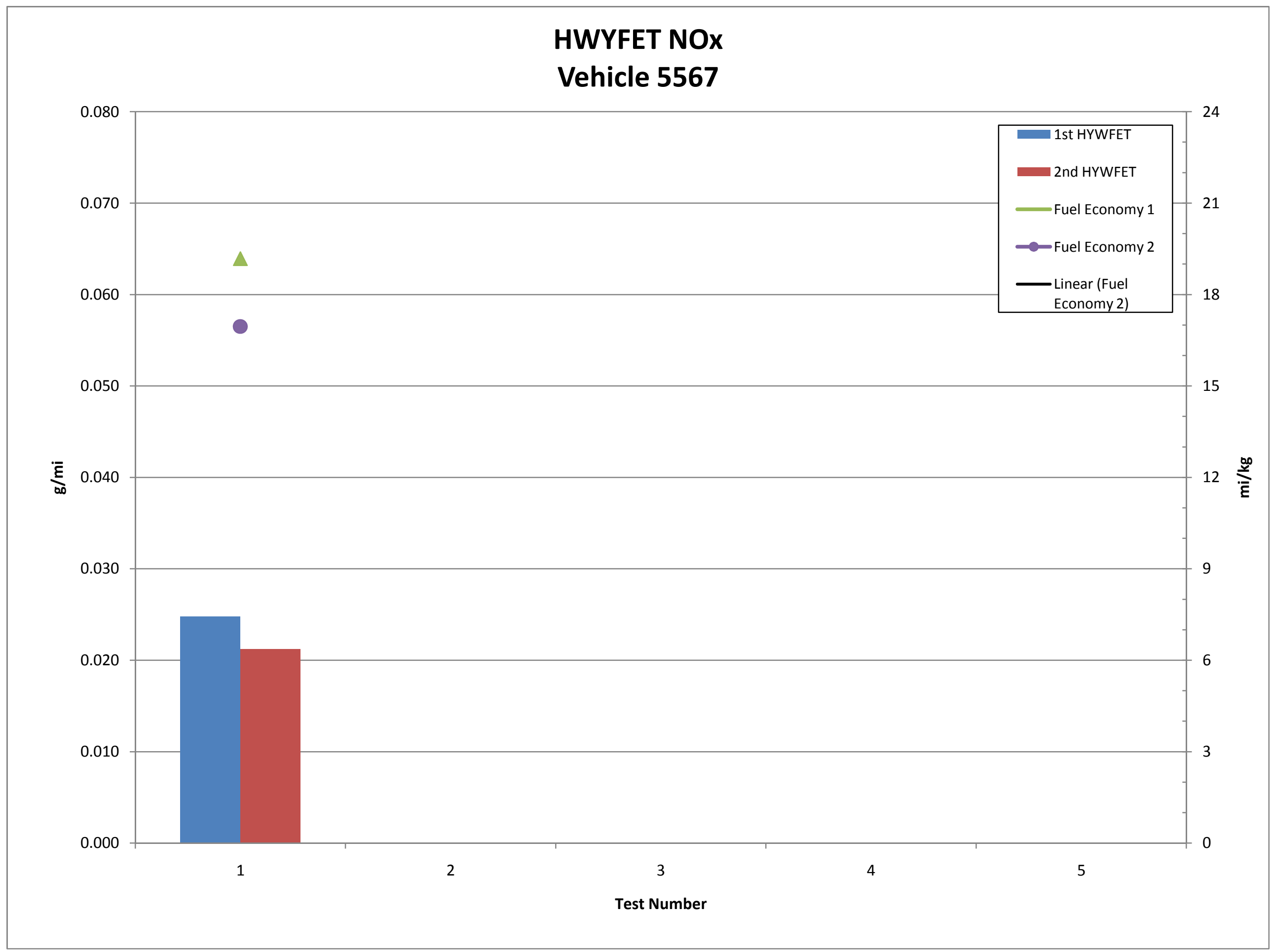

